\title{
REPORT TO THE ALLOYS RESEARCH COMMITTEE.
}

By Professon W. C. RoBER'IS-AUSTEN, C.B., F.R.S.

At the request of the Alloys Research Committee I began in Aprii 1890 to investigate the effects of small admixtures of certain elements on the mechanical and physical properties of Iron, Copper, and Lead. The Committee desired me to extend an investigation I had previously made upon the application of the "periodic law" of Newlands and Mendieleef to the mechanical properties of metals. This law, as originally expressed, states that "the properties of the elements are a periodic function of their atomic weights." It had already been shown that the effect of impurities added to gold is nearly proportional to their atomic volume, the larger the volume of the atom the greater being its effect ; $^{*}$ and it became interesting to determine whether this holds good for other metals.

The Committee considered it desirable that iron should be the metal first examined; but the problem has fortunately been attacked by M. Osmond, $\dagger$ the results of whose recent investigations have gone far to show that there are two distinct varieties of pure iron, the $\alpha$ or soft and the $\beta$ or hard form; and further that the action of impurities on iron does appear to be in accordance with the periodic law. The foreign elements, whose influence on the critical points of iron he has studied experimentally with more or less completeness,

* Philosophical Transactions of the Royal Society, vol. 179, 1888, p. 339.

† Comptes Rendus, vol. cx, 1890, p. 346. The results of his experiments are given in detail in the Journal of the Iron and Steel Institute, 1890, part 1, p. 38 . 
are ranged as follows in two columns in the order of their atomic volumes, found by dividing their atomic weight by their specific gravity:-

I.

$\begin{array}{ll}\text { Carbon } & 3 \cdot 6 \\ \text { Boron } & 4 \cdot 1 \\ \text { Nickel } & 6 \cdot 7 \\ \text { Manganese } & 6 \cdot 9 \\ \text { Copper } & 7 \cdot 1\end{array}$

II.

$\begin{array}{lr}\text { Chromium } & 7 \cdot 7 \\ \text { Tungsten } & 9 \cdot 6 \\ \text { Silicon } & 11 \cdot 2 \\ \text { Arsenic } & 13 \cdot 2 \\ \text { Phosphorus } & 13 \cdot 5 \\ \text { Sulphur } & 13 \cdot 7\end{array}$

He points out "that the elements in column I, whose atomic volumes are smaller than that of iron $(7 \cdot 2)$, delay during cooling cceteris paribus the change of $\beta$ or hard iron into $\alpha$ or soft iron, as well as that of "hardening carbon" (carbone de trempe) into "carbide carbon" (carbone de recuit). For these two reasons they tend to increase, with equal rates of cooling, the proportion of $\beta$ or hard iron that is present in the cooled iron or steel, and consequently the hardness of the metal. Indeed their presence is equivalent to more or less energetic hardening produced by rapid cooling. On the other hand, elements whose atomic volumes are greater than that of iron (column II) tend to raise, or at least to maintain near its normal position during cooling, the temperature at which the change of $(\beta)$ hard to $(a)$ soft iron takes place. Further, they render the inverse change during heating more or less incomplete, and usually hasten the change of dissolved or "hardening carbon" to "carbide carbon." Thus they maintain iron in the $(\alpha)$ soft state at high temperatures, and must therefore have the same effect in the cooled metal. In this way they would act on iron as annealing does, rendering it soft and malleable, did not their individual properties, or those of their compounds, mask this natural consequence of their presence. The essential part played by foreign elements alloyed with iron is therefore either to hasten or to delay the passage of iron during cooling to an allotropic state; and to render the change more or less incomplete, in one direction or the other, according to whether the atomic volume of the added impurity is greater or less than that of iron. In other words, foreign elements of low atomic volume tend to make iron itself assume or retain the 
particular molecular form which possesses the lowest atomic volume, whilst elements with large atomic volume produce the inverse effect.

It will be evident that if iron itself can exist in two widely different states, each with properties of its own, the mechanical properties of given samples of iron and steel must depend upon the relative proportions of the two modifications of iron present in the mass. And it will also be evident that the nature of the influence of impurities on iron is far more complicated than in the case of gold, their primary effect on iron being either to hasten or to delay the passage of the metal from its normal state to another, which possesses widely different molecular aggregation, and consequently different properties. In the case of gold, it is possible that the molecular constitution of the precious metal is simpler than that of iron; each molecule may consist of but few atoms, and therefore there may not be the same scope for pronounced change of properties which could follow re-arrangement of atoms in the molecules. The action of an impurity may probably be more direct in the ease of gold, as its influence is not initially exerted in re-arranging the atoms in a molecule, but in affecting the mutual relations of the molecules themselves. Or it may be that the lowering of the freezing point, which is effected by the presence of impurity, may enable the cooling gold to assume a crystalline structure which is detrimental to its tenacity, if not destructive of it.

The difficulties of obtaining for mechanical tests masses of iron with only definite amounts of a single impurity are very great, and it is therefore very difficult to extend Osmond's researeh; but of the practical importance of his experiments there can be no question, and their full significance may become more apparent by investigating the action of impurities on some other metal, the behaviour of which suggests strong probability that it can exist in an allotropic state. In view however of the importance of Osmond's research, it was considered desirable to confirm his main results, adopting an independent method of observation, as will be stated subsequently.

Lead, which is one of the metals the Committee selected for investigation, probably exists in more than one modification. 
Muschenbroeck and afterwards Guyton de Morveau* showed that the cohesive force or tenacity of lead is increased by hammering or drawing; and the latter speaks quite clearly of molecular strain produced by the mechanical treatment. Bolley $\dagger$ has shown that "chemically active" lead may be prepared by electrolytic action; and $W$. Spring $\ddagger$ has gone far to show that the polymerization (or increase in the number of atoms in a molecule) of leadtin alloys may take place at temperatures below their melting points. The observation made by Coriolis, $\$$ that lead increases in hardness by successive meltings, even if protected from oxidation, may not be without significance. I have made a great many experiments on the mechanical properties of lead as affected by a small quantity of impurity; but as yet it has not been found possible to obtain definite or even concordant results. The tenacity and extensibility of lead seem to be greatly influenced by the temperature at which the metal is cast; and the difficulty of avoiding the presence of flaws and blow-holes is very great. This portion of the enquiry has therefore been set aside for the present, as it is probable that more valuable evidence of allotropic changes will be afforded by thermal than by mechanical measurements.

Pyrometer.-In order to carry out the investigation, a really trustworthy Pyrometer is required. The admirable investigations of Callendar\| with the pyrometer of Siemens have restored the confidence in it which had been shaken by a Report of a Committee of the British Association. The action of this instrument depends on the variation of resistance presented by a heated platinum wire placed in one branch of a divided circuit; and it is trustworthy for temperatures up to $500^{\circ}$ C. or $900^{\circ}$ Fahr. Messrs. Callendar and Smith ** have shown that with platinum resistance thermometers a

* Annales de Chimie, vol. 1xxi, 1809, pp. 189-199.

† Liebig und Kopp, Jahresbuch, 1849, p. 278.

† Bulletin de l'Académie Royale de Belgique [3], vol. xi, No. 5, 1886.

\$ Annales de Chimie et de Physique, vol. xliv, 1830, p. 103.

II Philosophical Transactions of the Royal Society, vol. clxxviii, 1887, p. 161.

T Report of the British Association, 1874, p. 242.

** Proceedings of the Royal Society, vol. xlviii, 1890, p. 220. 
degree of aceuracy of the order of $0.01^{\circ} \mathrm{C}$. or $0.02^{\circ}$ Fahr. may be attained at temperatures between $100^{\circ}$ and $450^{\circ} \mathrm{C}$. or $212^{\circ}$ and $840^{\circ} \mathrm{Fahr}$.

In the present investigation it is necessary to measure much higher temperatures; and fortunately an accurate method is at hand. Early in $1889 \mathrm{I}$ had occasion to employ the pyrometer devised by M. H. Le Chatelier, and was satisfied as to its being extremely trustworthy and convenient up to temperatures over $1,000^{\circ} \mathrm{C}$. or $1,800^{\circ}$ Fahr. The instrument in fact enabled me to confirm the fundamental observations of ML. Osmond respecting the critical points of iron and steel, and to demonstrate the results in a lecture delivered before the members of the British Association in September 1889.* Le Chatelier's pyrometer I believe had not previously been employed in this country; and it may be well to describe it in some detail, as such an instrument has long been needed, and can hardly fail to be of much use to engineers. The pyrometer $\dagger$ consists of a thermo-couple of platinum, and platinum containing 10 per cent. of rhodium. Thermocouples have long been used; but, as is pointed out by Barus $\ddagger$ in an elaborate memoir only recently published, the earlier investigators unfortunately employed unsuitable metals, iron and palladium, which, from the readiness with which they absorb gases and consequently undergo molecular change, are of all metals probably the least suited for thermo-electric pyrometry. Osmond's work alone would show that iron is specially unsuitable for high-temperature thermo-couples. Le Chatelier's pyrometer is based on the measurement of the electric current produced by heating a thermo-junction inserted in a circuit with a galvanometer of considerable resistance. As already stated, this thermo-couple consists of two wires, each about $0.5 \mathrm{~mm}$. or 0.02 inch diameter, one of which is of pure platinum, and the other of platinum containing 10 per cent. of rhodium. The junction of the wires may simply be effected by twisting them together in either of the forms indicated by the sketches, Figs. 3 and 4, Plate 116.

* 'Nature,' vol. xli, Nov. 1889, pp. 11, 32 .

$\dagger$ Journal de Physique, vol. vi, Jan. 1887, p. 23.

$\ddagger$ Bulletin of the Unitel States Geological Survey, No. 54, 1889. 
The junction may be welded, or soldered with gold, no flux being used; but neither of these methods seems to possess any advantage over a double twist. This junction may be viewed as a battery; for when it is heated a current of electricity is generated, no other source of electricity being employed. It is asserted that even long wires of the platinum-rhodium alloy are homogeneous, and therefore do not give rise to subsidiary currents, which would disturb the effect of the main current produced by heating the junction; but very careful experiments to determine whether this is the case have yet to be made. From analogy with platinum-gold alloys, it may be doubted whether the platinum-rhodium alloy is of absolutely uniform composition. The thermo-electric properties of platinum-rhodium wire are said to be hardly altered by stress, or by exposure to rapid alternations of temperature; nor does the nature of the gaseous atmosphere in which the couple is placed appear to render its action untrustworthy. The present experiments have shown that the wires must certainly be protected from the vapour of silver, or from contact with carbon or silicon. The free ends of the platinum and platinum-rhodium wires are soldered to copper terminals, which are kept at a constant temperature by being plunged into test tubes, filled with alcohol and immersed in water, the temperature of which can be observed with a thermometer. The thermo-couple measures the difference of temperature between its heated junction and the copper terminals.

The galvanometer which appears to be best suited for use in connection with the couple is a reflecting dead-beat one, which bears the names of Déprez and d'Arsonval; it is now well known in this country. That employed in the following experiments * has an internal resistance of $200 \mathrm{ohms}$. The arrangement of the several parts is shown in Fig. 5, Plate 116, in which $U$ is a magnet, $B$ a coil of wire suspended by a german-silver wire SS and moving freely round an iron core $C$, and $M$ is a mirror carried by the same wire $S$. The steadiness of the spot of light upon the screen when the circuit is closed is remarkable.

* Constructed by M. Carpentier, 20 Rue Delambre, Paris. 
Graduation of Pyronneter.-The electromotive force produced by heating the thermo-junction to any given temperature is measured by the movement of the spot of light on the scale graduated in millimetres. A formula for converting the divisions of the scale into thermometric degrees is given by M. Le Chatelier; but it is far better to calibrate the scale by heating the thermo-junction to temperatures which have been very carefully determined by the aid of the air thermometer, and then to plot the curve from the data so obtained. Many fusion and boiling points have been established by concurrent evidence of various kinds, and are now very generally accepted. The following table contains thirteen of these:-

\begin{tabular}{|c|c|c|c|c|c|}
\hline $\begin{array}{l}212^{\circ} \mathbf{F} \text {. } \\
618^{\circ}\end{array}$ & $\begin{array}{l}\cdots \\
\cdots\end{array}$ & $\begin{array}{l}100^{\circ} \mathrm{C} \\
326^{\circ}\end{array}$ & & & $\begin{array}{l}\text { Boiling point of water. } \\
\text { Melting point of lead. }\end{array}$ \\
\hline $676^{\circ}$ & $\ldots$ & $358^{\circ}$ & - & $\cdot$ & Boiling point of mercury. \\
\hline $779^{\circ}$ & $\cdots$ & $415^{\circ}$ & - & - & Melting point of zinc. \\
\hline $838^{\circ}$ & $\ldots$ & $448^{\circ}$ & - & $\cdot$ & Boiling point of sulphur. \\
\hline $1157^{\circ}$ & $\ldots$ & $625^{\circ}$ & - & . & Melting point of aluminium. \\
\hline $1229^{\circ}$ & $\ldots$ & $665^{\circ}$ & . & . & Boiling point of selenium. \\
\hline $1733^{\circ}$ & $\ldots$ & $945^{\circ}$ & - & - & Melting point of silver. \\
\hline $1859^{\circ}$ & $\ldots$ & $1015^{\circ}$ & - & ${ }^{\circ}$ & potassium sulphate. \\
\hline $1913^{\circ}$ & $\cdots$ & $1045^{\circ}$ & - & - & gold. \\
\hline $1929^{\circ}$ & $\ldots$ & $1054^{\circ}$ & & - & copper. \\
\hline $2732^{\circ}$ & $\cdots$ & $1500^{\circ}$ & . & & palladium. \\
\hline $3227^{\circ}$ & $\ldots$ & $1775^{\circ}$ & " & • & platinum. \\
\hline
\end{tabular}

The known temperatures employed for calibrating the thermojunction referred to in this Report are the boiling point of water $100^{\circ} \mathrm{C}$, the melting points of lead $326^{\circ}$, zinc $415^{\circ}$, and aluminium $625^{\circ}$, the boiling points of sulphur $448^{\circ}$, and selenium $665^{\circ}$, and the melting point of potassium sulphate $1015^{\circ}$. The melting point of silver $945^{\circ}$ is one of the points which rests on more evidence than any other; I find however that, when it is carefully determined and interpolated in the curve, the number is only $920^{\circ} \mathrm{C}$; this is doubtless owing to retention of gas by the metal. The melting point of gold $1045^{\circ}$ C., and Violle's* determination of that of palladium

* Philosophical Magazine, vol. viii (series v), 1879, p. 501, and vol. xiii 1882, p. 147 ; Comptes Rendus, vol. Ixxxix, No. 17, pp. 702, 703. 
$1500^{\circ}$, are generally accepted. These several fixed temperatures have been used as the basis of the calibration.

In Fig. 2, Plate 115, some of these temperatures are taken as ordinates, while the abscissa are the deviations of the spot of light which marks the temperature at the thermo-junction. It will be evident, since these points fall so close to an even curve, that much confidence may be placed in the trustworthy nature of the pyrometer. It may be noted that the position here marked for the boiling point of water, namely at about $90^{\circ} \mathrm{C}$., is of course not the true boiling point of water, but is the difference between the true boiling point $100^{\circ} \mathrm{C}$. and the observed temperature $10^{\circ} \mathrm{C}$. of the cold junction of the pyrometer. In the various determinations the latter temperature varied from $10^{\circ}$ to $15^{\circ} \mathrm{C}$, or $50^{\circ}$ to $60^{\circ} \mathrm{Fahr}$.

It was hardly to be expected that the determination of the melting point of palladium would yield a figure which falls so fairly into line with lower melting points ; and it may be well to add a few details as to the manipulation. A globule of palladium weighing about 2 grammes or 30 grains may readily be melted by placing the metal in a cavity in a sound piece of charcoal. The charcoal near the button is ignited, and a stream of oxygen from a fine clay tube about $1 \mathrm{~mm}$. or 0.04 inch diameter is directed into the cavity. A very manageable source of intense heat is thus obtained; and a fused globule of gold or palladium may be tilted on to the junction conveniently placed in the cavity, and then allowed to cool there. The globule may in fact be melted on or shaken off the junction as readily as a drop of wax; and the slight arrests of the spot of light, which mark the true points of fusion and solidification, can readily be detected by a practised observer. It has already been shown by M. Le Chatelier that soldering the junction with gold in no way diminishes its sensitiveness; and this appears to be true of palladium. The wires however, after brief exposure to the alloying metals at this very high temperature, rapidly become destroyed and broken. In some cases, as in that of determining the melting point of potassium sulphate, the thermo-junction may be plunged without covering into the midst of the mass, which is gradually being raised to its fusion point. In the case of a metal, the thermo-junction may 
either be surrounded by a portion of the metal; or a strip or globule of the metal may be placed in a crucible filled with some substance difficult of fusion--silica or calcined magnesia-in close proximity to the thermo-junction. The temperature is very gradually and steadily raised, until the metal begins to fuse; a Fletcher oxygen furnace answers well. The moment at which fusion begins is indicated by an arrest in the movement of the spot of light; followed, if the mass of metal be small, by a rapid forward movement when the fusion is complete. The point that the spot of light has attained on the graduated scale at the moment of its arrest is the point to note as the melting point of the metal. A little practice will enable this point to be readily determined; but all uncertainty in the matter is removed. by reducing the spot of light to a fine vertical line, and securing a photographic record of its movement.

The following plan may therefore be recommended when a high degree of accuracy is required. The vertical line of light, from an argand gas burner L and mirror H, Fig. 1, Plate 115, is reflected from the mirror IN of the galvanometer, and is allowed to fall upon a sensitized plate through a carefully adjusted horizontal slit A B; Eastman's gelatine films have been found to answer well. The slit entirely crosses the plate, which is made to travel upwards at a uniform rate by gearing $\mathrm{D}$ driven by clockwork; the regularity of the rate of travel may be tested by a time-signal in seconds, produced by periodically obscuring, by the interrupter $\mathrm{E}$ worked by a clock, the light from a second fixed mirror $\mathrm{F}$ placed immediately below the suspended mirror $\mathbf{M}$ of the galvanometer, so as to send a fixed beam of light to the zero of the galvanometer-mirror scale, that is, to the further end of the horizontal slit AB. The amplitude of the deflection of the galvanometer mirror $\mathrm{M}$ will of course depend on the temperature to which the thermo-junction $T$ is heated. The same source of light illuminates both mirrors; and the result is, first, a beaded datumline from the intermittent light of the fixed mirror $F$, which gives the rate of travel of the plate; and second, a continuous curve which is photographically traced by the line of light from the galvanometer mirror M, this photographic curve being the resultant of the movements of the tiny spot of light and of the sensitive plate. The 
sketch shown in Fig. 1 is about one-twelfth of the actual size of the pyrometer employed in connection with this Report.

The nature of the photographic curve in the case of a melting point may be illustrated by that which represents the fusion and solidification of a mass of aluminium weighing 10 grammes or 150 grains. The thermo-junction was in this case protected by a thin covering of pipe-clay $1 \mathrm{~mm}$. or 0.04 inch thick. While the plate is at rest, the spot of light traces the straight line ef, Fig. 9, Plate 116; then as the plate advances it traces the somewhat sinuous curve $f g$, owing to the necessarily irregular heating of the mass of metal; but it is arrested at $a$ when fusion begins, and a line parallel to the datum line is traced until the mass is fluid, when the temperature is raised above the melting point, as is shown by the portion of the curve marked $b$. The gas being then turned off, the metal cools and freezes, as is indicated by the second arrest $c$, at a point slightly below its melting point.

It will be evident that a chronographic record might replace the photographic one. In fact in beginning the investigation the chronographic method was employed. The time taken by the spot of light from the galvanometer to pass each division of a transparent graduated scale was noted on the paper ribbon of a delicate Bain instrument by an electric signal, side by side with a series of electric time signals from a clock beating half-seconds. This method, though very delicate, involves much labour in the translation of the ribbon and in plotting the curves, and is therefore much less convenient than the photographic one, which gives a curve automatically.

The calculations by which the final results are obtained are as follows. From the curve representing a particular experiment the temperature of any point of interest may be obtained by reference to the calibration curve. This temperature has to be corrected, first, for error $e$ in indications of the galvanometer, due to change of its temperature; and second, for alteration $j$ in the temperature of the cold junctions.

The measurement of temperature by the thermo-junction depends, as is well known, on the measurement of an electromotive force by means of the current set up in a circuit of known resistance. 
'Theoretically there are a number of corrections to make, such as those which arise from the varying resistance of the junction itself, and of the leads; but the comparatively high resistance of the galvanometer renders these insignificant. Thus the resistance of the wires forming the couple was in one experiment $2.42 \mathrm{ohms}$, of the leads $0 \cdot 175 \mathrm{ohm}$, and of the galvanometer 201 ohms. The part of the wires heated to a high temperature was too short to form an appreciable part of the resistance, even if its own resistance were doubled. Consequently the first correction $e$ reduces itself to a simple temperature correction, applied to the galvanometer. This at first sight might appear to involve several corrections:- -first, a correction for change $c$ in resistance of the coil B, Fig. 5, Plate 116; second, a correction for variation $v$ in the torsion of the suspending wire $\mathrm{S}$; third, a correction for any modification $m$ of the magnetic field of the galvanometer.

The correction for change $c$ in resistance of the coil is easily made. The coil is of German silver, which has a temperature coefficient of 0.00038 per degree centigrade. The deflection at the melting point of gold was 16 centimetres upon the particular scale employed; hence a rise in temperature of $1^{\circ} \mathrm{C}$. decreases the deflection from 16 to $15 \cdot 994$.

The variation $v$ in the torsional resistance of the suspending wire was found to be quite negligible. Time readings were taken of the oscillations of the mirror, 500 consecutive oscillations being taken several times each day on different days and at different temperatures. No difference in time of oscillations greater than 0.2 second could be detected with a stop-watch. One indirect effect however was observed. The pillar of the instrument supporting the wire and coil does not appear to be made of the same material as the suspending wire itself; and as this suspending wire has some initial torsional strain, the zero of the instrument changes slightly with changes of temperature. After this was discovered, special care was taken to watch the zero.

The modification $m$ of the field in which the coil hangs is probably very small; any alteration would be at once checked and provided for by the system of introducing known high temperatures.

The temperature as indicated by the deflection of the mirror has also to be corrected for variation $j$ in the temperature of the cold 
junctions. Obviously the pyrometer measures only the differences of temperature between the cold junction of the copper terminals and the heated junction of the thermo-couple; but by keeping the former at one temperature the indications of the pyrometer are measures of the differences between this temperature and that of the heated couple. The curve connecting the deflections with their corresponding temperatures is very nearly a straight line throughout the range of the experiments ; and consequently it is legitimate to add to or subtract from the deflection an amount corresponding with the small variation of the cold junction from some normal temperature taken at $18^{\circ} \mathrm{C}$. This correction and that for change in resistance of the coil of the galvanometer are applied to the observed deflection produced by the source of heat, the temperature of which was to be determined. This deflection is then compared with the deflection (also corrected) that is obtained by the introduction of known high temperatures, usually afforded by a crucible filled with pure molten gold; and the difference, multiplied by the constant obtained from the part of the calibration curve (of the particular wire) which corresponds to the range of temperature, gives the difference in degrees centigrade from the known high temperature.

If the thermo-junction be ruptured, the ends of the wires may be joined again after the removal of the defective part. Nevertheless in conducting a series of experiments it is very desirable to employ for as long as possible the same thermo-junction; and it is therefore necessary to adopt precautions with a view to its preservation. This gives rise to considerable difficulty, in view of the absolute necessity for bringing the couple into close proximity to the molten metal; and several methods of protecting the couple were adopted. Clay coverings were open to the objection of their fragility under sudden exposure to heat; and this entails the risk of spoiling a thermocouple in the midst of an investigation. Enclosing the junction in little tubes of iron filled with silver answers very well for comparatively low temperatures; but iron alloys readily with many metals into which the tube would have to be inserted; for instance, the iron-protected junction could not be plunged into molten gold. Ultimately blocks were cut from portions of large "plumbago pots" 
used in mint work, and were carefully fashioned in the lathe into small crucibles of the ordinary shape, but provided with a tube or socket extending vertically from the base up to about one-third the height of the crucible, as shown in the section, Fig. 6, Plate 116. The thermo-couple could then be inserted in the tube, which was surrounded by the molten metal. The Morgan Crucible Company have since made crucibles of this pattern specially for this research. This plan was independently devised for the purposes of the present research; it had however been anticipated by Barus, * who used a similar arrangement on a larger scale for determining the boiling points of metals. In ascertaining the point of solidification of a metal, the crucible filled with metal is withdrawn from the furnace, and placed over the thermo-junction so that the wires are near the top of the tube, but do not touch its sides. To prevent them from doing so, a cap made of sheet platinum is always kept fitted over them, and probably is specially useful in protecting the platinum wires from being contaminated with silicon and carbon, which Callendart has already shown to increase the resistance of platinum wires; they certainly injure the wires mechanically.

Liquation of Silver-Copper Alloys.-In order to gain some evidence as to the capabilities of the appliance, it was subjected to the following tests in connection with the liquation of silver-copper alloys, that is, the separation of their more fusible constituents. This series of alloys has previously been the subject of eareful experiment, and much is now known respecting them. Not the least interesting fact connected with them is the remarkable molecular re-arrangement they undergo during solidification. Levol, $\neq$ who is the chief authority on the subject, concluded that the only homogeneous alloy contains 71.893 per cent. of silver and $28 \cdot 107$ per cent. of copper; and he considers it to be a definite combination

* Bulletin of the United States Grological Survey, No. 54, 1889, p. 92.

† Philosophical Transactions of the Royal Society, vol. clxxviii, 1887, p. 161.

† Annales de Chimie et de Plyysique, vol. xxxvi, 1852, p. 193; vol. xxxix, 1853, p. 163. 
of the two metals having the formula $\mathrm{Ag}_{3} \mathrm{Cu}_{2}$. Nany years ago I also examined the behaviour of the silver-copper alloys during cooling; and the following figures and diagram, Fig. 7, Plate 116, taken from my paper,* may be given, as showing the way in which a cubical mass, $45 \mathrm{~mm}$. or $1 \frac{3}{4}$ inch side, will arrange itself in cooling

Alloy containing 92.5 per cent. Silver and $7 \cdot 5$ per cent. Copper, cooled rapidly. (See Fig. 7, Plate 116.)

\begin{tabular}{cc|cc|cc}
$\begin{array}{c}\text { Central } \\
\text { Vertical } \\
\text { Plane. }\end{array}$ & $\begin{array}{c}\text { Percentage } \\
\text { of } \\
\text { Silver. }\end{array}$ & Corners. & $\begin{array}{c}\text { Percentage } \\
\text { of } \\
\text { Silver. }\end{array}$ & Sides. & $\begin{array}{c}\text { Percentage } \\
\text { of } \\
\text { Silver. }\end{array}$ \\
$a$ & $92 \cdot 46$ & $h$ & $92 \cdot 32$ & $q$ & $92 \cdot 36$ \\
$b$ & $92 \cdot 60$ & $i$ & $92 \cdot 37$ & $r$ & $92 \cdot 38$ \\
$c$ & $92 \cdot 91$ & $h$ & $92 \cdot 33$ & $s$ & $92 \cdot 31$ \\
$d$ & $93 \cdot 55$ & $l$ & $92 \cdot 33$ & & \\
$e$ & $93 \cdot 10$ & $m$ & $92 \cdot 39$ & & \\
$f$ & $92 \cdot 50$ & $n$ & $92 \cdot 38$ & & \\
$g$ & $92 \cdot 42$ & $o$ & $92 \cdot 27$ & Dip assay & $92 \cdot 51$ \\
& & $p$ & $92 \cdot 32$ & &
\end{tabular}

Maximum difference, between centre $d$ and corner $0,1 \cdot 28$ per cent.

rapidly. It will be evident that the silver becomes concentrated towards the centre of the mass, which is richer in silver by 1.28 per cent. than the external portions.

The results of a memorable research led Guthrief to the conclusion that certain alloys in cooling "throw off atomically definite bodies, leaving behind a fluid mass which is not definite in composition;" so that ultimately the most fusible alloy of the series is left, which he calls the eutectic or most fusible alloy, and in it the "proportions between the constituent metals are not atomic proportions." Guthrie's experiments dealt only with alloys of low melting-points, such as the fusible metals; but photographic records of the rate of cooling, as measured by the platinum and platinum-rhodium thermo-couple, might be expected to show at what temperatures groups of silver-copper alloys solidify, and fall out of solution. And at the same time evidence as to the probable composition of the eutectic alloy of the series should be as readily

* Proceedings of the Royal Society, vol. xxiii, 1874-5, p. 481.

$\dagger$ Philosophical Magazine, vol. xvii, 1884, p. 462. 
obtained by these means as it was, in the earlier experiments, by placing an ordinary mercurial thermometer in a bath of fusible metal.

Fig. 11, Plate 117, represents such a photographic record of the rate of cooling of a mass of standard silver weighing $11 \mathrm{oz}$. It will be seen that the initial temperature indicated is $1068^{\circ} \mathrm{C}$, and that there is a fall to $856^{\circ} \mathrm{C}$. at $b$, when the freezing of the mass as a whole begins. But before this abrupt turn in the curve takes place, there is a slight change in its direction at $a$, probably caused by a falling out of alloys rich in copper. After the abrupt break at $b$ a slight upward tendency $c$ shows that heat is evolved; but the curve continues to fall until another abrupt change occurs at $748^{\circ}$ at $d$, which indicates that a second critical point has been reached. That this is attended by the evolution of heat is seen, for the spot of light remains stationary for forty seconds; and it is doubtless caused by the solidification of the eutectic alloy, that is, the most fusible alloy of the series.

Similar photographic records of the cooling of Levol's alloy $\mathrm{Ag}_{3} \mathrm{Cu}_{2}$, containing $71 \cdot 893$ per cent. of silver, show that there is only a single break, Fig. 11, which occurs at this same temperature $748^{\circ} \mathrm{C}$; solidification throughout the mass then takes place. A record of the cooling of a mass of silver-copper, $\mathrm{Ag} \mathrm{Cu}$ containing 63.029 per cent. of silver, also gives only a single break at $748^{\circ} \mathrm{C}$; ; but although the freezing point of the eutectic alloy is evidently close to this temperature of $748^{\circ} \mathrm{C}$., it would not be safe to conclude that either $\mathrm{Ag}_{3} \mathrm{Cu}_{2}$ or $\mathrm{Ag} \mathrm{Cu}$ is itself the eutectic alloy; they are probably only the last alloys (in which the constituents are in simple atomic proportions) to fall out of a bath of indefinite composition. Other alloys of this series have been examined, and the curve of the one containing 60 per cent. of silver is also shown in Fig. 11. It seems to show that in a series of alloys the second point of solidification is not quite constant. The behaviour of a solidifying mass of gun-metal appears to present exactly the same characteristics; but the experiments have not as yet been concluded. It is easy in the case of alloys like fusible metal to keep the alloy melted, and to ascertain what the composition of the most fusible alloy really is, 
by repeatedly straining the fluid mass from the suspended crystals through a canvass or asbestos bag. The temperature required to separate the eutectic alloy of the silver-copper series would introduce many difficulties of manipulation, though the result might ultimately be obtained.

The accompanying photographic curve, Fig. 12, Plate 118, shows the application of the photographic method to recording the evolution of heat which occurs in cooling masses of steel. The experiment was made on a piece of the same steel which had already been subjected to experiments by M. Osmond. It had the following composition:carbon 0.160 per cent.; silicon 0.012 ; sulphur. 0.021 ; phosphorus 0.029 ; manganese 0.110 per cent. The results of cooling it are shown by the upper curve in Fig. 12. It will be observed that, as the mass cooled down, there were, as M. Osmond had shown, two distinct evolutions of heat: one $d$ occurs at $843^{\circ} \mathrm{C}$. or $1549^{\circ}$ Fahr., which is believed to mark the change of hard to soft iron, because it occurs also in iron free from carbon; and the other $f$ is at $675^{\circ} \mathrm{C}$. or $1247^{\circ}$ Fahr., and is certainly due to the change in the relation between the carbon and the iron. There is probably also another slight evolution of heat $e$ at $767^{\circ} \mathrm{C}$. or $1413^{\circ} \mathrm{Fahr}$. It is interesting to compare this curve with the one below it, obtained during the cooling of a mass of steel containing nearly 0.5 per cent. of carbon, in which there is a distinct evolution of heat at $820^{\circ} \mathrm{C}$. or $1508^{\circ} \mathrm{Fahr}$., and a prolonged one at $650^{\circ} \mathrm{C}$. or $1202^{\circ} \mathrm{Fahr}$. With reference to these curves M. Osmond himself wrote to me on 18th Dec. 1890, "the photographs are very beautiful, but, as you say, this mode of representation [by time-temperature curves] is not well adapted for showing slight evolutions of heat which occur while the cooling of the mass is slow [and is represented by the flat part of the curve]. It is certain however that the slightest prominence shown in the curve is a real one, and is not due to errors of plotting. The curve representing my steel is perfectly clear; but your specimen appears to have been well chosen for showing the two critical points."

Effect of small quantities of impurity on the freezing point of Gold.The fundamental effect of an impurity in modifying the mechanical 
properties of metals has been abundantly established; but the part played by the impurity may be twofold. It may act directly on its own account upon the mass; and, by changing its structure, may alter its mechanical properties when solid. Or, as Osmond's * work has shown, it may cause, retard, or hasten the passage of a metal in which it is hidden from its normal to an allotropic state, and may affect its properties indirectly. For the purpose of investigating these two distinct sets of phenomena, gold offers many advantages. It may be prepared in a very high degree of purity; it is not liable to contamination by oxidation; and much is already known respecting certain of its mechanical and thermal $\dagger$ properties as influenced by small quantities of impurity, which exert a truly astonishing influence on its strength and extensibility. Platinum would no doubt be even better; but its manipulation is attended with many difficulties. In the case of gold such difficulties can be met; and when they have been surmounted the work may be carried on with confidence, so as to prepare for the extension of the experiments to metals in ordinary use. It would appear therefore most desirable to obtain thermal evidence as to the influence of impurities on a cooling mass of gold. In what degree, for instance, is the freezing point of gold influenced by the presence of definite impurities? and is the final solidification of the mass preceded in the respective cases by a pasty stage? or does the passage from the fluid to the solid state take place rapidly? Many years ago I called attention to the remarkable lowering in the melting point of gold, produced by the presence of silicon; but the want of a suitable pyrometer has hitherto prevented my making direct experiments upon the subject.

The method of preparing gold of a high degree of purity has already been described. $\ddagger$ In each experiment now to be more fully described, 132 grammes or 2,037 grains of gold were melted in one of the crucibles provided with a central tube or socket as already described, and weighing with its cover 180 grammes or 2,006 grains.

* Comptes Reudns, vol. cx, 1890, p. 84 l.

$\dagger$ Annales de Chimie et de Physique, vol. xx, 1880, p. 66.

$¥$ Philosophical Transactions of the Royal Society, vol. elxxix, 1888, pp. 339-349. 
The initial temperature of the molten mass was high, somewhere about $1,200^{\circ} \mathrm{C}$. or 2,200 $\mathrm{Fahr}$; and the durability of the thermo-junction and the constancy of its readings had therefore to be carefully tested. It was found by repeated trials that different crucibles of the same size, filled with identical weights of gold, gave closely concordant results; but it occasionally happened that the platinum wire of the couple became brittle and broke. In such cases the fractured portion was removed, and the ends were twisted together again. Throughout the course of the experiments, a crucible filled with pure gold was kept at hand, and the freezing point of the molten metal was determined from time to time as a check.

The object of the experiments was primarily to ascertain whether the influence of impurities on the metal was really tangible, that is, whether the insertion of the point of a fine stirrer of clay would indicate the existence of a pasty or gritty stage; but advantage was taken of the installation of the appliances to determine what retardation of the freezing point of gold is produced by the known elements which are added to it.

The result of Raoult's investigations on the lowering of the freezing points of solutions led him to the conclusion that one molecular proportion of any substance, dissolved in a hundred molecular proportions of any solvent whatever, lowers the freezing point of that solvent $0 \cdot 62^{\circ} \mathrm{C}$. or $1 \cdot 12^{\circ} \mathrm{Fahr}$. This had not been tested in the case of solutions of metals in metals, until Heycock and Neville* began an elaborate investigation of the subject. Their research, as far as it has at present been carried, deals first with the lowering of the freezing points of sodium and tin, produced by the addition to them of certain other metals; and second, with the molecular weights of metals when in solution. The results of their experiments when compared with the empirical laws of Coppet and Raoult may be briefly stated as follows. They are in accordance with the law "that for moderate concentration the fall in the freezing point is proportional to the

* Riemsdijk, Journal of the Chemical Society, vol. 1v, 1889, p. 666; vol. 1vii, 1890, pp. 376 and 656. 
weight of the dissolved substance present in a constant weight of solvent." By making the assumption that the molecule of zinc or of mercury is monatomic when in solution in tin, they confirm the second law "that, when the falls produced in the same solvent by different dissolved substances are compared, it is found that a molecular weight of a dissolved substance produces the same fall whatever the substance is." But the third law, which states "that, if a constant number of molecular weights of the solvent be taken, then the fall is independent of the nature of the solvent," they found to be probably incorrect; and theoretical considerations indeed would lead us to expect this. In the case of silicon in standard gold, which has already been mentioned, a long semi-fluid stage appears to be set up ; the metal may contain solidified particles, and yet be sufficiently fluid to flow readily; this phenomenon has not yet been fully investigated.

In a research of much interest, Ramsay* has determined the molecular weight of a number of metals by Raoult's vapour-pressure method: that is, he ascertained the depression of the vapour-pressure of the solvent, produced by a known weight of dissolved substance, and he finds that, although sodium behaves irregularly, yet "it would appear legitimate to infer that in solution, as a rule, the atom of a metal is identical with its molecule, as the physical properties of those metals which have been vaporised would lead us to suppose."

The experiments were conducted as follows. The gold was melted in the crucible, and its freezing point noted in two ways:first, by recording with the aid of a chronograph the rate at which the mass cooled, the results being plotted in a curve with time and temperature as co-ordinates. The exact freezing point was then indicated by the abrupt change in the direction of the curve. Second, the freezing point was also actually observed in the following way:-the cover of the crucible had an orifice, which could be covered with a plug of charcoal, and through this orifice was inserted a fine pipe-clay rod held in the hand. A little experience with this, in tonching the surface of the molten mass, enabled the

* Journal of the Chemical Society, vol. 1v, 1889, p. 521. See also Tammann, Zeitschrift für physikalische Chemie, 1889, p. 441. 
existence of either a pasty or a gritty stage to be detected, and the point of actual solidification to be noted; and this point was telegraphed on to the chronograph tape by a distinctive sign. The gold was then re-melted, and the impurity to be added was carefully weighed, wrapped in pure gold foil, and added to the molten mass, which was well stirred with a fine clay stirrer, and replaced in the furnace to make sure that the mass was thoroughly fluid. The crucible was placed in position over the thermo-junction, and the freezing point observed as before. Lead and bismuth exert a great influence in diminishing the tenacity and extensibility of gold; and they were therefore first selected with a view to study their action upon its freezing point. In the gold-lead series, Fig. 10, Plate 116, the full curve $A$ is the normal line, representing the freezing of pure gold; and the dotted curves B C D were obtained as the results of successive additions of lead, $B$ corresponding with 0.2 per cent., $\mathrm{C}$ with 0.4 per cent., and $\mathrm{D}$ with 0.8 per cent. of lead. The lowering of the freezing point was found to be proportional to the amount of lead added. No marked pasty stage was detected; and the lowering of the freezing point appears to be about $19^{\circ} \mathrm{C}$. or $34^{\circ}$ Fahr. for every atom of lead added to a hundred atoms of gold.

The ealculations are as follows. The atomic theory assumes that there are as many atoms in 196 parts by weight of gold as there are in 208 parts by weight of lead. Consequently if 0.2 per cent. of lead be added to a mass of gold, there will be $0.2 \times 196 \div 208$ $=0.19$ atom of lead per hundred atoms of gold. Dividing the observed fall of the freezing point in degrees centigrade by the number of atoms of impurity which causes it in a hundred atoms of gold, the figure known as the "atomic fall" is obtained; and this is nearly constant for any given mass of an individual metal. As soon as 0.3 per cent. of lead is present, oxidation causes a little trouble; and apparently a simple molecular action gives place to one of more complex character, the result being that the further alteration of the freezing point is not so great as it was initially.

The series with bismuth showed a very regular lowering of the temperature of the freezing point, giving an atomic fall of $17^{\circ} \mathrm{C}$. or $31^{\circ}$ Fahr. up to. 2 or 3 per cent. of bismuth. Even with 19 per cent. 
of bismuth there is a point well marked in the curve, showing where solidification commences. A study of these curves gives rise to a suspicion that a "trace" of impurity has an important effect upon the latent and specific heats; but until the experiments are repeated under very accurate calorimetric conditions, this point is uncertain. Bismuth probably gives a entectic alloy of very low melting point, the pasty stage being maintained down to temperatures differing but little from that of melting lead; but the experiments have not been carried further at present. It is remarkable that a small quantity of bismuth in gold produces a lead-grey or almost purple colour of the fractured surface, which, upon burnishing, becomes at once golden yellow. This is doubtless due to the very distinct liquation that can be observed, the granules of nearly pure gold being surrounded by a brittle and impure mass.

Platinum gave an interesting series of results, which indicated an atomic fall of $17^{\circ} \mathrm{C}$. or $31^{\circ} \mathrm{Fahr}$. But gold is very soon saturated with platinum; apparently 0.6 per cent. is sufficient for that purpose. The first addition of platinum at once stopped the "piping" of the solidifiying mass, which is so marked a feature in very pure gold; and gave the characteristic crystalline surface which indicates the presence of platinum. An accident prevented the series from being carried beyond 1 per cent. of platinum, which amount however is sufficient to raise the freezing point again to that of pure gold.

Silicon, which has a small atomic weight, exerts a great influence on the freezing point of gold; but much difficulty was experienced in getting it to alloy with the gold. The fall produced was at the rate of $16^{\circ} \mathrm{C}$. or $29^{\circ} \mathrm{Fahr}$. for each atom in a hundred atoms of gold.

Manganese was also somewhat difficult to alloy; but after the union of the gold and manganese had been effected, the mass behaved in a peculiar way, indicating considerable internal changes in their mode of association near the freezing point. The bath remained quite mirror-like and limpid until the freezing point was reached; it then suddenly clouded over, and a granular mass began to form. The results were remarkable from the fact that the atomic fall was found to be only one half that obtained in most other cases; thus there is reason to conclude that manganese exists in this particular instance as a diatomic molecule. 
The effect of aluminium was also studied, on account of the interest it possesses in connection with the metallurgy of iron. The gold combined with this metal with avidity, and when cold the fracture showed very marked granular structure. A study of the curve indicates that an almost chaotic state is produced in the gold by the addition of aluminium: not only is the point of initial freezing lowered, but the metal only partially solidifies during a very long range of temperature, and could easily be poured at several hundred degrees lower than the initial freezing point. This in all probability is the reason for the conflict of opinion as to the amount and nature of the change produced in the freezing point of wrought-iron by the presence of aluminium, as in the case of the well-known "mitis" castings. The long pasty stage which aluminium sets up is very deceptive, and renders it diffeult to determine which is the true freezing point. Aluminium has a low atomic weight, and causes a very considerable fall in the freezing point of gold ; this fall however is only one-third of that produced per atom by other impurities.

Silver occupies a remarkable position in the series. Very pure silver was used, which had been tested by Stas; but it required nearly 5 per cent. of silver to cause any appreciable lowering of the freezing point. Whether solid gold is capable of dissolving silver cannot yet be proved; but it opens an extremely interesting field for research.

Steel.-From the engineer's point of view the most interesting information which the pyrometer has as yet afforded is connected with the measurement of internal stresses in iron and steel. Osmond's work has shown that molecular changes take place in steel; and it is evident that the occurrence of these changes must be of vital importance when the metal is subjected at high temperatures to mechanical operations such as rolling or forging. The question naturally arises, do the molecular changes in the iron take place at one moment throughout the mass of metal? that is, is the rate of cooling approximately uniform throughout the mass? Or does the external portion of a hot ingot cool so much more rapidly than the centre as to allow the molecular changes in the iron, and the alterations in the relation between the carbon and the iron, to 
become completed near the surface long before they take place in the interior of the mass? The experimental difficulties in the way of obtaining information upon these points have hitherto appeared to be insuperable; but the pyrometric method used in this research affords most important evidence, as a brief description of the following experiments will show.

Two thermo-junctions made from adjacent pieces off the same coils of wire, and both insulated in the ordinary way by means of pipe-clay tubes, were carefully prepared. A miniature ingot of mild steel, four inches diameter and eight inches long, shown in section in Fig. 8, Plate 116, was provided by the Director-General of Ordnance Factories; one hole 5-16ths inch diameter was drilled from the centre of one end to a depth of four inches; and another bole of the same diameter was drilled near the edge of the same end to a depth of one inch. The ingot was then heated to bright redness in a furnace; and when it had been withdrawn, the two thermo-junctions were inserted, one in each of the holes. Then by means of a special switch they were alternately connected for short but measured periods of time with the galvanometer of the photographic recording apparatus. Curves were thus obtained from both the thermo-junctions simultaneously, each curve being made up of short dashes. In the case of mild steel the evidence as to molecular change was but slight; but with a similar ingot of moderately hard steel the results, which are shown in Figs. 13, 14, and 15, Plates 119 to 121, are very interesting. This ingot contained 0.799 per cent. of carbon, 0.084 per cent. of silicon, and 0.412 per cent. of manganese.

In Fig. 13, Plate 119, which represents the cooling of the ingot in air, the upper curve records the cooling of the centre of the ingot, and the lower the cooling of the outer portion. The initial temperature at the centre was $1,160^{\circ}$ C. or $2,120^{\circ} \mathrm{Fahr}$. The molecular change in the iron can be detected at $880^{\circ}$ C. or $1,616^{\circ}$ Fahr., and the carbon change takes place at $696^{\circ} \mathrm{C}$. or $1,285^{\circ}$ Fahr. In the lower curve, representing the cooling of the circumference, the carbon change takes place no less than four minutes earlier than at the centre, and at the lower temperature of $665^{\circ} \mathrm{C}$. or $1,229^{\circ}$ Fahr., as compared with $696^{\circ} \mathrm{C}$. or $1,285^{\circ}$ Fahr. This 
is a most interesting point, as Osmond has already shown that the rate of cooling has a measurable effect upon the temperatures at which molecular change occurs. The great internal strain which must be set up between the points marked $A$ and $B$ in the upper curve is evident when it is borne in mind that the carbon change is accompanied by a considerable alteration of rolume.

In Fig. 14, Plate 120, is shown a pair of curres obtained from the same ingot when cooled by a water-spray. These present but few additional points of interest.

In the experiment represented by Fig. 15, Plate 121, the ingot was plunged, when its exterior was at a temperature of $850^{\circ} \mathrm{C}$. or $1,560^{\circ} \mathrm{Fahr}$, into a tank of cold water. The lower curve however, representing the rate of cooling of the outer portions of the ingot, is not strictly autographic, as it was slightly defective on the original photographic plate for temperatures below $600^{\circ} \mathrm{C}$ or $1,100^{\circ} \mathrm{Fahr}$. The upper curve is autographic throughout.

In all these experiments it was found that the flow of heat from the centre of such an ingot was not sufficiently rapid to prevent there being considerable variations in temperature within the mass. There can be but little question that such experiments well deserve careful attention, and in the hands of competent observers should be fruitful of results.

The Committee anthorised me to secure the services of an assistant to aid me in conducting these researches. Mr. H. C. Jenkins, Whitworth Scholar and Associate of the Royal School of Mines, was accordingly chosen, and has proved himself to be a patient and careful experimenter, and has shown that he possesses manipulative skill of a high order. 


\section{Discussion.}

Professor Roberts-Austen exhibited the pyrometer actually employed in this research, Fig. 1, Plate 115, but taken out of the case in which the sliding sensitized plate was made to travel for tracing the photographic curve. He showed the action of the instrument during the heating and cooling of a small piece of iron, the beam of light reflected from the galvanometer mirror being seen to pause in its movement in either direction as soon as the temperature was reached of $850^{\circ} \mathrm{C}$. or $1,560^{\circ}$ Fahr., at which the thermal change took place, indicating the corresponding transformation in the nature of the iron.

He explained that while, according to the "periodic law," as originally expressed, "the properties of the elements are a periodic function of their atomic weights," it seemed easier, with regard to the mechanical properties of metals, to trace the influence of their atomic volumes than of their atomic weights: the atomic volume of an element being found by dividing its atomic weight by its specific gravity. A singular fact then came out. It was necessary first of all to find some particular metal on which the effect of traces of impurity could best be tried; and for many reasons gold appeared to be the most favourable for snch an investigation. Copper might be added to gold, and would increase its tenacity; but the addition of a trace of lead or bismuth to gold resulted in the production of a mass as brittle as loaf sugar ; and by adding to gold a constant quantity, namely 0.2 per cent., of various impurities, the singular fact was discovered that the tenacity was rapidly affected in inverse proportion to the relative volume of the added impurity: that is, as plotted in the diagram, Fig. 16, Plate 122, the elements which had atomic volumes larger than that of gold tended to diminish its tenacity, while those which had smaller volumes tended to increase it. Therefore when an element was added which had a much larger atomic volume, as in the case of bismuth, the gold so alloyed had practically no tenacity at all. It was this singular fact which had led Dr. Anderson to propose to the Council of the Institution of Mechanical Engineers that a committee should be appointed to ascertain how far the same result followed generally 
(Professor Roberts-Austen.)

with the metals most used in mechanical engineering, when traces of other elements were added to them; and he would take this opportunity of recording his gratitude not only to Dr. Anderson, but also to the Institution, for the welcome encouragement offered to himself as a metallurgist to bring before them a matter so important to their interests.

The need for applying such investigations to iron became daily more and more evident indeed; but the questions presented themselves at the outset-did iron always behave itself properly? was it always in the normal state in which engineers mostly knew it? or might it behave like many other elements, and pass from a normal state to an allotropic? Many elements were known to possess such a dual state. Carbon might appear in its graphite form, or in its diamond form; silicon in its graphitic, or in its diamond; phosphorus in its red or its yellow modification. Sulphur was most familiarly known in its crystalline and brittle variety, of which a specimen was here exhibited; but if this ordinary sulphur was melted and poured into water at a certain temperature, though it underwent no other change and was still absolutely pure sulphur, it became a plastic substance, of which a specimen was also shown, resembling india-rubber; and if again this plastic sulphur was heated to a temperature of about $90^{\circ} \mathrm{C}$. or $190^{\circ}$ Fahr., it suddenly evolved heat and passed back into the original crystalline state. Nothing had been changed in its composition, no other ingredient had been added; the transformation was simply a passage from one state to the other. He believed, though he was not absolutely sure, that if in its plastic state it was stretched beyond its limit of elasticity it was thereby made to pass into the crystalline variety; experiments which Professor Kennedy and himself had been making upon it in that way during the reading of the report had gone far to convince them that this was really the case, and if so it was a very curious fact. What he wanted now to insist upon was that here was one and the same substance existing in two such widely different states. Was iron capable of behaving in this way? Was it capable of taking advantage of any condition in which it might find itself, and of rearranging the atoms of its molecules, and so passing from 
one state to another? Many observers, beginning with Joule, thought that this was the case; but of all experimenters M. F. Osmond of Paris, whose name recurred so often in the report just read, had perhaps made the most definite advance in this direction. Osmond had shown that, if a piece of iron were allowed to cool in contact with Le Chatelier's thermo-electric pyrometer, as it cooled down from a bright red heat of over $1,000^{\circ} \mathrm{C}$. or $1,800^{\circ} \mathrm{Fahr}$. to a temperature of $850^{\circ} \mathrm{C}$. or $1,560^{\circ} \mathrm{Fahr}$, the march of the spot of light indicating the cooling continued perfectly regular and uniform; but as soon as ever the temperature of $850^{\circ} \mathrm{C}$. was reached, the iron showed evidences of some change: for a few seconds heat was evolved, and the spot of light remained stationary. Osmond stated that in its red-hot condition iron was really in the $\beta$ or hard state. Owing to the temperature indeed, its molecules were only united loosely, and therefore it was true the red-hot mass as a whole was soft; but the individual molecules, if they could really be got at or could be resolved into their atoms, would be found to be hard. As soon however as the iron cooled down to the temperature of $850^{\circ} \mathrm{C}$. there was an evolution of heat, just exactly as there was when the plastic variety of sulphur passed into the crystalline; and Osmond urged that at this temperature the iron became changed into the $\alpha$ or soft state. Now supposing that, instead of pure iron, the cooling were observed of carburized iron, that is, of steel; then it was found that not only was there the one distinct evolution of heat, which Osmond believed to be due to the passage of the iron from the hard state to the soft, but there was also another distinct evolution of heat at about $675^{\circ}$ C. or $1,247^{\circ} \mathrm{Fahr}$., which he was satisfied was due to the change in the relation between the carbon and the iron.

The whole question as to the allotropy of iron turned on such evidence as it might be possible to collect of the passage of pure iron itself, free from any other ingredient, from one state to another, as indicated by the evolution of heat, which was widely admitted to be the main test of the passage from one state of aggregation to another. Osmond thought he had satisfied himself upon this point by finding that electro-deposited iron showed such an 
(Professor Roberts-Austen.)

evolution of heat while it was cooling down. Now it was known that electro-deposited iron was hard; and its hardness might be due either to its structure, arising from the method by which it was deposited, or to the fact that it retained within itself a large volume of occluded hydrogen. By means of the pyrometer he had tried to get a step further. A little piece of electro-deposited iron had been Leated in a vacuum by the arrangement sketched in Fig. 17, Plate 122 ; it was enclosed in a porcelain tube $P$, and the two wires from the pyrometer were passed in through the one end to the iron $I$, and a tube passing through the other end was attached to a Sprengel mercurial pump, whereby the porcelain tube was rendered perfectly vacuous, so that the iron could be heated in a vacuum by raising to bright redness the portion of the tube where the iron was situated. As the temperature rose, the occluded hydrogen gas began to come off, and at the temperature of $200^{\circ} \mathrm{C}$. it was freely evolved and soon exhausted itself; and then there was a perfect vacuum in which the heating of the iron could be continued. The usual photographic record of the heating or the cooling of such a piece of iron in vacuo could therefore be readily obtained. Moreover it was easy, by obscuring the source of light for a moment, to obtain a break or indication in the curve at the points where the evolution of gas began and ended. The evolution ceased, and the perfection of the vacuum was restored, before the iron reached a temperature of $400^{\circ} \mathrm{C}$. Any change thenceforth observed must be due to a change either in the iron itself or in some impurity contained in it; if the iron was really pure, it must be due to the iron itself, and to nothing else. As soon as the temperature reached $850^{\circ} \mathrm{C}$., there was a distinct absorption of heat. Barrett had shown that recalescence, or the evolution of heat during cooling, was a reversible property: that is, during the heating of the same substance there was an absorption of heat, or a certain quantity of heat became latent, at the same temperature at which the evolution had occurred during cooling. The autographic curve drawn during the heating was shown in Fig. 18, Plate 122, and formed a branch of the investigation which had been added since the report was written. Proceeding still further, the temperature was raised to 
$900^{\circ} \mathrm{C}$.; and then, as the iron was allowed to cool, the converse occurrence took place at $850^{\circ} \mathrm{C}$, namely evolution of heat, due to ehange in the iron. Thus electro-deposited iron deprived of its hydrogen exhibited the reversible property of recalescence. The only question that remained was, did the iron contain carbon? The experiment by Osmond proved to be not absolutely conclusive, as the electro-deposited iron had in that case been found to contain 0.08 per cent. of carbon. Though a mere trace, it seemed far from certain whether even so minute a quantity of carbon might not be sufficient to produce mischief. A particular piece of electro-deposited iron, which he himself had subjected to the foregoing treatment in a vacuum, had therefore been analysed for him by one of the most competent analysts he knew, Mr. Edward Riley; by whom the presence of carbon had indeed been detected, but to the extent of only 0.007 per cent., which had possibly come from a speck of dust. However, if the objection to the view that iron could assume an allotropic state was thought to be supported by the detection of so minute a proportion of carbon, he was afraid he had at present no answer.

There was one other piece of evidence to which he wished to call attention, as to the possibility of the existence of iron in the $\beta$ or hard state. When a mass of iron or steel was being heated, as soon as it reached a certain temperature, varying according to its composition between $600^{\circ}$ and $700^{\circ} \mathrm{C}$, or $1,100^{\circ}$ and $1,300^{\circ}$ Fahr., it ceased to be magnetic; it was well known that red-hot iron was not magnetic, and the contention was that in red-hot iron the metal existed in the $\beta$ or hard form. In one of the most remarkable metallurgical investigations of the past few years, Mr. Hadfield had dealt with a series of alloys of iron with manganese, and had shown what remarkable properties they possessed. One fact bearing upon the present research was that, if iron contained more than 7 per cent. of manganese, it did not show in cooling the evolution of heat characteristic of other varieties of iron. Then, according to the theory advocated by M. Osmond and himself, such a material should be hard, however slowly it was cooled; and such proved to be the case. Further, if the iron was present in the $\beta$ or hard form, the mass should not 
(Professor Roberts-Austen.)

be magnetic in the cold; and it was not magnetic, as was proved by experiment. In this connection he thought the experiments which had been made on the cooling of the miniature ingot of mild steel (page 565) really deserved far more careful attention than it had yet been possible to give them. They marked indeed only the first breaking of the ground for a long investigation. M. Osmond had written to him within the last few days, stating that he considered this to be one of the most important directions in which investigation could possibly be extended.

At one of the Research Committee meetings the President had asked that attention should be given to the alloys of copper, with special reference to the quality of copper used for the fire-boxes of locomotives at the present time. He had carefully sought for evidence of any allotropic change being produced in copper by heating and cooling, but had not been able to find it. He did find however that the presence of only one per cent. of arsenic rendered copper much stronger, not only at ordinary temperatures, but also at temperatures to which copper used for locomotive fire-boxes might be subjected. When this portion of the investigation had been further followed, he hoped to have a more complete answer to the question raised by the President.

Anyone who had to conduct experimental investigations would know how much depended upon the nature of the assistance he could obtain; and he was glad therefore to refer to the efficient aid he had received from Mr. Jenkins, who had already manifested his qualifications as a metallurgist.

Dr. Wriblam Anderson, Vice-President, and Chairman of the Alloys Research Committee of the Institution, noticed a contrast between the paper on boiler construction, read on the preceding evening, and the report to which they had just listened. The former contained scarcely a particle of theory: whereas the report now presented was naturally full of theory, but theory of a most important kind, though possibly the practical bearing of the research which Professor Roberts-Austen had been conducting with so much skill might not be quite so apparent at first sight as it would 
certainly become later on. Too much stress could not be laid on the discovery, if it might so be called, of the Le Chatelier pyrometer. In the first place it was a means of ascertaining very high temperatures with absolute certainty. The calibration curve in Fig. 2, Plate 115, showed what reliance might be placed upon it; and the extreme smallness of the twisted junction of the two wires, Figs. 4 and 8 , Plate 116, enabled them to be inserted with great ease in any substance, of which it was desired to ascertain the temperature. In the next place this discovery gave even now, and he could not help thinking it would do so still more in the future, a wonderful power of ascertaining the quality of a mass of steel in every part from one end to the other. Hitherto, in the case of large forgings, specimens might indeed be got from the two ends, and be tested mechanically. But these left in absolute darkness the quality of the intermediate portions of the mass. Of course one of the causes of the variation in the different parts of a steel forging was liquation, that is, alteration in the chemical composition of the mass by the separation of its more fusible constituents: in consequence of which the nature of the two ends and of the middle portion might not necessarily be the same; and if it was not the same, the metal would behave differently under the treatment to which the whole forging was subjected. In the case of gun steel especially, which assumed the form of long tubes and hoops-the inner tubes of some of the larger guns being nearly 50 feet long, and some of the hoops 12 or 14 feet long, 4 feet diameter, and 6 inches thick - the ends could be tested, but the middle had to be taken for granted. Now however, with the aid of this pyrometer, by taking the mere shavings that were turned out in boring or in rifling, and heating them and then letting them cool and describe autographically their own curves of cooling, it was almost certain, if the curves described by the cooling of shavings taken from every part of the forging were identical, that the composition of the forging must be everywhere the same. When more came to be known about this mode of testing, he thought that it would be possible to tell whether the physical condition of the forging was the same throughout. 
(Dr. William Anderson.)

Molecular changes took place in steel, in consequence of its being in various states of tension. Just as Professor RobertsAusten had indicated in the, case of sulphur, which from its amorphous or plastic condition could by stretching be brought back to the crystalline form, so steel under severe tension undoubtedly altered its composition; and this being the case, it seemed probable that, if specimens taken from the steel were subjected to the process of cooling and of tracing their curves of cooling, the autographic curves would indicate whether there was any change, and whether there was any difference in the quality of the steel in various portions of the mass. When a change was thus indicated, of course attention would be drawn to the matter, and the effects of the change counteracted by proper treatment. For instance, forgings which were made at several heats, and were consequently in an unequal state from being partly hot and partly cold, if re-heated and properly annealed afterwards might be restored to a uniform condition throughout. The result of the researches which the Institution had started he was in great hopes would be to give a practical power of determining the internal state of the material, which would be of the utmost possible value, especially now that such enormous masses were beginning to be dealt with. The Institution he hoped would persevere with the work; it would take a long time, and the absolute results might be long of attainment; but they would certainly be reached at last.

Mr. Robert A. Hadfield, as a member of the Alloys Research Committee, considered they had been exceedingly fortunate in getting such an able and energetic worker as Professor Roberts-Austen to take up the preliminary scientific investigations of this important subject. Having himself made probably about as many experiments as any one else in this special field of research, he knew full well how great a want there was of helpers working on scientific lines like Professor Roberts-Austen, whose excellent address at the recent Cardiff meeting of the British Association upon the present state of metallurgical science was most acceptable to all interested in keeping up to date their acquaintance with metallurgical matters. In the 
present discussion he hoped something would be heard from Mr. Howe of Boston, Massachusetts, whom he was sure all would be glad to see and welcome, not only on account of his own valuable treatise on the metallurgy of steel, but also as one of the hosts who last year in America had so handsomely entertained among the members of the Iron and Steel Institute many who were members also of this Institution. Such helpers were wanted to collate and arrange the results arrived at in the work of practical men, who amidst the engagements of their ordinary business, whilst able perhaps to produce valuable alloys, had not the time necessary to complete tho investigation and organization of their own results.

In the report now presented by Professor Roberts-Austen there seemed to him to be certain anomalies, to which he desired in no captious spirit to draw attention, in order that some of the points raised might undergo further and fuller examination. With reference firstly to the two columns of foreign elements given in page 544 as affecting the properties of iron, he thought some modification was required in their classification, in order to be in agreement with the facts known as to the physical qualities of alloys of iron with these elements. His own attention having been devoted to alloys of iron alone, a further statement he thought might advantageously be added to the report, giving roughly the general characteristics, so far as known, of the alloys produced with these elements. To take one case, a considerable number of experiments had convinced him that, notwithstanding the atomic volume of copper being $7 \cdot 1$, while thut of iron was $7 \cdot 2$, it ought not to be placed in column I along with carbon, boron, nickel, and manganese, as producing similar effects. Its effects totally differed, and he had not found any points of resemblance. This opinion had been confirmed by correspondence with M. Brustleiu, who had worked on such alloys of iron. Copper should probably be classed with sulphur, phosphorus, and arsenic, and perhaps with silicon and aluminium. Apparently it did not confer hardness, and did not delay the change of $\beta$ or hard iron, if such existed, into $\alpha$ or soft iron: judging at any rate from those alloys of copper and iron that he had to do with. 
(Mr. Robert A. Hadfield.)

Again, in a recent interesting communication to the French Society of Chemistry (Bulletin 1891, pages 840-3) respecting the allotropic transformations of metals, M. Le Chatelier said that the results of a considerable number of his experiments pointed to the existence of only a limited number of allotropic changes; and that therefore the variability in the physical properties of metals could not be explained by their existence in an unlimited number of slightly different isomeric states. M. Le Chatelier considered that molecular or crystalline transformations were due rather to changes in internal structure-that is, in the forms and sizes of the crystals or grains of metals in juxtaposition, and also in the mode of distribution of the impurities - than to changes in chemical character. In other words the changes that occurred were of a structural nature, and were produced by physical treatment, as distinguished from chemical action.

The following was an approximate classification which he had attempted in the light of experiments thus far made with alloys of iron that had come under his own observation; it was simply approximate, and was not drawn up as anything more than a suggestion with a view of further consideration.

Class 1. Carbon.

„2. Nickel, and Manganese.

"3. Chromium, and Tungsten.

4. $\{$ A. Aluminium, and Silicon.

"4. $\{$ B. Sulphur, Phosphorus, Arsenic, and Copper.

Not yet classed-Lead, Tin, Cobalt, Bismuth, and Cadmium.

In class 1 he had placed carbon by itself. Neither experiment nor theory could get away from the fact that carbon alone produced "water-quenched hardness" in steel : that is, it alone conferred upon iron the property of becoming hard when water-quenched, and of acquiring such a degree of hardness as would enable it to scratch glass and to form the cutting edge of tools. He was informed by Professor Roberts-Austen that boron would do the same; but not having himself seen proof of this yet, he could not offer any positive statement of his own on this point. Samples of iron alloys which had been referred to by M. Osmond as containing boron were of so 
small a size that he thought it would hardly be safe to generalize from them; and he should like to see larger pieces made and tested. "The hardness in "self-hardening" steel was equally due to carbon; and makers of such steels could confirm the statement that these steels could not be self-hardening without a large percentage of earbon being present in them. In analyses of self-hardening steel that had come under his own observation there had always been a large proportion of carbon present. The hardness due to carbon was alike produced, whether the carbon was added or alloyed by itself with iron, or whether it was present in the iron along with other elements, such as chromium, a hard metal, or aluminium, a soft metal. As an example and a proof of the latter point, he had obtained good cutting tools with an alloy containing 97 per cent. iron, 2 per cent. aluminium, and 1 per cent. carbon : the softening effect of the 2 per cent. of aluminium being apparently masked by the presence of the 1 per cent. of carbon. Another special characteristic also possessed by carbon was that in small quantities it produced powerful effects, as already pointed out in Professor Roberts-Austen's report. For instance, as little as 0.05 per cent. difference from a certain standard prodnced steel unsuitable for the particular purpose in view. This characteristic certainly did not apply to many others of the elements that were used for alloying with iron. With some of these a difference might occur of six or eight times as much as the above, with but little change in the physical properties of the alloy.

In class 2 he would place nickel and manganese. These were elements which when added in sufficient quantities strongly stiffened iron, but did not confer the property of water-quenched hardness. Their effect most nearly approached, whilst greatly differing from, that of carbon; and they might also be termed hardeners, though of less intensity; but in no case did they give water-quenched hardness. In other respects however these two metals did not both of them produce by any means the same results. Steel with 3 per cent. of manganese was comparatively brittle in its forged state, while 3 per cent. of nickel gave a tough material. Then with increasing quantities of the latter, after exceeding 9 per cent. there was no 
(Mr. Rober't A. Hadfield.)

development of the extraordinary strength noticed with manganese steel.

In class 3 he placed chromium and tungsten. These elements stiffened iron, but acted much less powerfully than those in class 2. They also did not confer the property of water-quenched hardness. For instance, in chromium steel, should carbon also be present, the chromium then acted powerfully in retaining the carbon in or combined with the iron as "hardening carbon." Steel containing 2 per cent. of chromium, and in which the carbon was not more than 0.12 per cent., would not harden even if water-quenched at a white heat. As soon as the carbon increased, then the hardening properties also increased. A 2 per cent. chromium steel with say 1 per cent. of carbon would harden more readily and to a greater depth, as compared with steel containing the same percentage of carbon only, and devoid of chromium. Only recently he had obtained a sample of steel containing nearly 15 per cent. of chromium, which could be forged; but he would not advise yet any attempt at such a mixture, because the forging could not be done readily. The remarkable toughness of certain kinds of special chromium steel, such as was produced by his own firm, had been shown in a trial of one of their 6-inch armour-piercing shells, made with special large core, which had penetrated a compound plate of a thickness equal to the calibre of the projectile, and had been found uninjured nearly a mile and a quarter on the other side of the plate. In another case one of their 6-incl shells of ordinary armour-piercing pattern, and of similar quality, had been fired unbroken through two separate compound plates, each 9 inches thick; it had thus punched through 18 inches of compound plate, and had still remained uninjured. When fired a third time against a specially prepared compound plate, made on the EllisTressider plan by Messrs. John Brown and Co., it had met its fate; but it had taken three plates to beat one projectile. The peculiar fact in connection with this kind of steel was that chromium, whilst itself probably a very hard metal-he said probably, because he had never been able to obtain a sample of pure chromium-would yet not produce in the absence of carbon any apparent increase in the Lardness of the iron with which it was alloyed, at any rate up to 
3 or 4 per cent. This fact was so far in confirmation of the position assigned to chromium in the report, where it was placed in column II (page 544) among the elements tending to keep iron soft; and he was glad to call Professor Roberts-Austen's attention to it for what it might be worth.

In class 4 he would include aluminium, silicon, sulphur, phosphorus, arsenic, and copper. Whilst agreeing in their general properties of not conferring hardness upon iron, these six might preferably be separated into two groups, $A$ and $B$, group $A$ comprising aluminium and silicon, and group $B$ the four others. Though aluminium was a metal and silicon a metalloid, these two certainly agreed together remarkably in many of the effects they produced, though not in all. They did not act so powerfully in destroying malleability and toughness as the four others forming group B; but as soon as they exceeded say 3 per cent. the resulting alloys of iron possessed similar qualities to those imparted by the four in group B. The alloys of iron with aluminium and with silicon did not possess much commercial value, though he had obtained several remarkable results with the metalloid silicon up to as high as 2 or even $2 \frac{1}{2}$ per cent. The proximity in the atomic volumes of aluminium $10 \cdot 6$ and silicon $11 \cdot 2$ was worthy of note, seeing the similar results they produced when alloyed with iron.

In group B of class 4, sulphur, arsenic, and copper, when present in but small quantities, acted similarly in destroying malleability and ductility either in hot or in cold iron. Phosphorus also produced a somewhat similar effect, but might be present in larger quantities before red-shortness occurred; it caused serious brittleness in cold iron, as was well known, at any rate as regarded steel. All the above alloys, even with small percentages, were soft, brittle, and of little value. They differed from the alloys of group A in several respects.

As to iron alloyed with lead and tin, his own experiments had not been very successful. With lead it seemed impracticable to get a true alloy or combination; in fact the whole of the lead added had been found at the bottom of a steel ingot $2 \frac{1}{2}$ inches square, not alloyed at all and apparently unchanged. It seemed to him a rather 
(Mr. Robert A. Hadfield.)

remarkable circumstance for a metal having such a low melting: point as lead to be found apparently unchanged at the bottom of an ingot of another metal whose melting point was ten or twelve times higher.

Some experiments had been made with cobalt. When alloying $1 \frac{1}{2}$ per cent. he had found the iron forged well, but did not possess hardness. Bismuth had been tried, but the experiments were yet incomplete. The same remark applied to cadmium; if the results with it should turn out to be of any interest, he should be glad to communicate them to Professor Roberts-Austen, who had told him that he thought results of special interest might be obtained with this metal. As gold and silver were at present so scarce in steel works, nothing had been done in the direction of alloying iron with them. Faraday was reported to have experimented with silver steel, and a material bearing this name had been made in Sheffeld; but he need hardly say such steel contained no silver.

Though necessarily rough and approximate, he thought that the foregoing classification, based upon the results obtained from the alloys produced, might be borne in mind before adopting as definite a classification such as that indicated in the report. The work of the Research Committee would be received with much interest by those concerned in metallurgical matters. It was therefore of the greatest importance that the theory so ably advocated by M. Osmond and also by Professor Roberts-Austen, and having so much in it that was attractive, should be most carefully verified.

With regard to pyrometers, too much could not be said in praise of the work done by Professor Roberts-Austen, who had now given a most interesting and valuable result of his labour, much of which would be of excellent service in practical working. At present there was one drawback with the pyrometer described in the report, when it was applied to determine temperatures of metals with high melting points, arising from the fact that the platinum-rhodium wires, when immersed say in molten steel, became brittle, and it was hardly possible to get more than one reading, and even then of doubtful accuracy. On this point perhaps Mr. Howe would give his opinion, as he had made considerable use of the pyrometer. If some method 
could be devised of getting over this difficulty, he thought the instrument would really be a practical one and of great service. After the great amount of trouble taken by Dr. Anderson and Professor Roberts-Austen, it would have been most acceptable if the cooling diagrams from the samples tested of commercial steel had happily afforded more definite results; he trusted however that further experiments would be made. Without doubt much was to be gained by correct observation of the cooling curves, on the excellent method devised by Professor Roberts-Austen, to whom were due special thanks for the great amount of time and thought he had devoted to this investigation. From his present report it was evident that this interesting subject offered great scope for research, if systematically carried out; and he believed that discoveries were yet to be made which would prove of the utmost value to the future progress of mechanical engineering.

Mr. Henry M. Howe, Boston, Massachusetts, thought the theory was certainly most attractive that the effect produced in a metal by impurities or foreign ingredients was a function of their atomic volume. As he understood from a former paper by Professor Roberts-Austen, not only the tenacity but also the melting point should be a function of the atomic volume. That is, the effect produced on the melting point as well as on the tenacity of a metal by slight additions of foreign elements was a simple function of the atomic volume of those elements. In the case of iron, the effect of an addition of carbon was unquestionably to lower its melting point. On the now theory therefore, should not the addition of a small quantity of phosphorus, coming as this element did at the other end of the scale of atomic volumes in page 544, raise the melting point? But such evidence as at present existed, he thought, showed that phosphorus did not tend to raise the melting point of iron. There might be some way of explaining this; but at any rate, looking at the effect in general cf foreign substances on iron, he thought that according to present knowledge copper and carbon could not readily be classed together in the same group. The position taken by MC. Osmond which attracted the most notice and 
(Mr. Henry M. Howe.)

opposition seemed to him not to be that there was an allotropic change in iron during cooling: this he thought he was prepared to admit, for the fact had long ceased to be questioned that iron suddenly lost its magnetism and suddenly regained it, not gradually, but with a leap at a critical temperature. There was no reason he thought to suspect that it had anything to do with the presence of carbon, or of anything but iron. But M. Osmond went a little further, and maintained that the hardening of iron on sudden cooling was not due to any change or difference in the condition of the carbon, as had been believed; but was due to the allotropic change in the condition of the iron itself; and apart from all his experimental skill, it had to be seen whether any evidence had been offered by him which supported his view.

The Le Chatelier pyrometer seemed to him to be one of the greatest boons that metallurgists had ever received, enabling them to measure high temperatures, even up to whiteness, with great convenience, rapidity, and accuracy. The accuracy indeed was astonishing. While not able yet to speak positively, his experience led him to hope that comparative results might under favourable conditions be got with an error of not over $2^{\circ}$ C. or $4^{\circ}$ Fahr.; and absolute results with an error of not over $10^{\circ} \mathrm{C}$. or $18^{\circ} \mathrm{Fahr}$, or perhaps even not over half as much. Careful manipulation by skilful hands was of course required for such a degree of accuracy; but even with the rougher handling which might be looked for in industrial establishments he thought there was no reason why the error should exceed $20^{\circ}$ or at most $30^{\circ} \mathrm{C}$., or say $40^{\circ}$ to $50^{\circ} \mathrm{Fahr}$, even with such high temperatures. As to rapidity, this was one of the greatest merits of the instrument. It might be illustrated by a particular case. Supposing that the temperature had to be observed simply of some one point or object, then of course absolutely continuous observations could be obtained if desired : so that the rapidity was absolute, the time taken between the observations being infinitesimal. But supposing it were wished to control the temperature of say twenty heating furnaces: then all that had to be done was simply to embed permanently in the brickwork of each furnace a thermo-electrical couple, from which a wire was led 
to a switch-board in connection with a single galvanometer. By means of the switch-board the galvanometer could then be connected with one of the furnaces after another, or any one at will; and without any great hurry he saw no reason why the temperatures should not be determined of at least five furnaces in a minute. Having himself used the galvanometer under like conditions, if he remembered aright his observations had been even more rapid than this. Not more than eight seconds he thought were required to make any one observation, switehing from one thermo-junction to another. The United States were now arming their coasts with large mortars, or vertical guns, cast on the Rodman principle round a water core, which purposely induced a severe stress in the steel in cooling. It was important to study the difference between the rate of cooling on the outside of the gun and in the bore; but hitherto there had been no ready means of ascertaining or controlling the rate of cooling on the outside of the gun. The rate of cooling in the bore could be got readily from observing the heating of the water; but now, in an investigation which he should take up on his return, it was intended to embed in the mould in which the gun was cast a series of thermo-electrical couples, so as to determine at very short intervals the temperature of a great number of points on the outside of the gun as it was cooling. Thence later would of course be ascertained the relation between the rate of cooling on the outside and in the bore, and the consequent stress in the gun. Such a series of observations seemed to resemble those made by Professor RobertsAusten on the cooling of the outside and inside of ingots, as described in the report (page 565); and he fully agreed with him as to the importance of this field for research.

Professor J. O. Arnold, Sheffield, questioned whether the plan thus far pursued in this research, of which the present report was the introduction, did not entail a great waste of precious labour, with small prospect of any good result, at any rate in connection with iron and steel. Such comparatively simple substances as gold and lead seemed to him not likely to furnish any useful analogies for investigating so marvellously complex a substance as steel, which he 
(Professor J. o. Arnold.)

considered to be far more important for engineers to study; and however fascinating might be the theories presented in the report, steel research was in his opinion a field of too national an importance to be used lightly as a cantering ground for the hobbies of periodicity and allotropy. The report appeared to him to be really an abridgment of M. Osmond's paper on the critical points of iron and steel, read before the Iron and Steel Institute (Journal 1890, No. I, page 38); and Professor Roberts-Austen appeared to assume a responsibility for the whole of M. Osmond's theory, much of which the speaker believed to be untenable. It might be well to point out, for the information of those who had not had an opportunity of seeing M. Osmond's own diagrams, that the prominence therein given to the points of recalescence during the cooling of a piece of steel was represented in Professor RobertsAusten's diagram, Fig. 12, Plate 118, by nothing greater than the three tiny ledges at $d, e$, and $f$, in the autographic curve obtained from another piece of the same steel (page 558). Such minute deviations from the smoothness of the rest of the fair curve, drawn by the admirable photographic recorder, were hardly sufficient in his opinion to be taken as an indication of so important a change as would be that of hard into soft iron.

It was somewhat startling to metallurgists to find that chromium, silicon, and tungsten were classed in page 544 among elements which softened steel; but a little further down in the same page their softening action was qualified by the proviso, "did not their individual properties, or those of their compounds, mask this natural consequence of their presence." Such a qualification seemed to him to deprive the classification of all value, and to lead nowhere. Engineers ought to be told what were the properties of alloys of these various elements with iron and steel, if any use was to be made of them.

Hardness had been several times mentioned in the report, and also in the original paper by M. Osmond; but the fact seemed to have been ignored that there were different kinds of hardness, such as abrasion hardness and brittle hardness. A steel which was quite soft to the drill or the turning tool might nevertheless be 
quite brittle under the hammer; and the hardness which rendered it brittle was a different kind of hardness from that of a turning tool. Annealing was defined in the original paper by M. Osmond as rendering iron soft and malleable by slow cooling. But annealing as carried out in M. Osmond's experiments was not annealing at all, in the proper sense in which the term was used by engineers and steelmakers. If a steel casting in a dry sand mould were left in its mould for fifteen hours, it cooled from fluidity to (say) a milk-warm heat. It was slowly cooled, and according to M. Osmond's idea it had been annealed. But a casting of average hardness so treated would be very brittle under the hammer. If however immediately after being cast it was placed in an annealing furnace, and was maintained at a fair red heat for as much as seventy hours, and was then allowed to cool gradually, the effect of such long annealing was that it became possessed of great toughness. These different states of steel appeared to him not to have been taken into account by either Mr. Osmond or Professor Roberts-Austen, yet they were of the utmost practical importance. In connection with M. Osmond's theory of hard and soft iron, it was represented in the report (page 558) that the point $d$ in Fig. 12, Plate 118, probably marked the change from hard to soft iron in the mild steel containing 0.16 per cent. of carbon. It seemed to be believed that this very small perturbation or halt in the autographic record marked what would really be a gigantic internal convulsion, a complete change of hard iron to soft iron: that is to say, that iron when it was heated was in the hard state, and on cooling, if the steel were soft, it passed into the soft state. Mroreover the theory was that earbon had an influence upon the extent of this change, and that in a steel low in carbon the iron passed almost entirely into the soft state in cooling, while in a steel high in carbon the carbon retarded the passage of the iron from the hard to the soft state. Yet this very diagram, Fig. 12, Plate 118, seemed to him to furnish evidence against such a theory altogether. If the first pause at $d$ marked the change from the hard to the soft state of iron, it would be expected that in a mild steel the halt would be much more marked, because the change would be so much more complete; and 
(Professor J. O. Arnold.)

that in a steel high in carbon, as the change was somewhat. retarded by the carbon, the pause would be less marked. But as a matter of fact it would be observed that the lower curve in Fig. 12, drawn by the harder steel, presented a rather greater perturbation at the temperature $d$, where the iron was supposed to be passing from the hard into the soft state.

For some thirty years past Dr. Clifton Sorby of Sheffield had been making some remarkable researches into the microscopic structure of steel; and his results were not theories based on the slow or fast movement of a beam of light, but must be regarded as actual facts. The latest research which he had laid before the Iron and Steel Institute (Journal 1887, No. I, page 255) showed that steel was one of the most remarkable bodies in the world, either artificial or natural. In steel, just within the range of microscopic vision, was found a remarkable compound structure, called by Dr. Sorby the "pearly constituent," consisting of alternating laminæ of unequal thickness and of different composition. As far as his observations had gone, they had tended to confirm the theory that the thicker laminis were pure iron free from carbon, and the thinner ones were carbide of iron. The thickness of the thinner lamina was about 1-80,000th of an inch, and of the thicker about $1-40,000$ th of an inch. And in all the specimens he had tried of true steels, when properly prepared and magnified about 700 diameters under the microscope, Dr. Sorby had found that there constantly cropped up this remarkable structure. There was no doubt whatever that the changes in the structure of steel on hardening had an enormous influence upon its physical properties; and a reference to Dr. Sorby's microscopic researches on this subject, which he had himself almost entirely confirmed by a laborious investigation, seemed to him to be absolutely necessary in the discussion of the report now presented.

Turning to the really valuable work which had been done in this research, he was glad to call attention to the fact that, while II. Osmond had reduced into definite form the crude theories of recalescence which had been in existence for some time, and had shown certainly within fairly accurate limits the temperatures at 
which recalescence really took place, Professor Roberts-Austen had now confirmed these temperatures by his autographic curves. The lower curve in Fig. 12, Plate 118, and the upper in Fig. 13, Plate 119, showed a great evolution of heat at a temperature a little below $700^{\circ} \mathrm{C}$. or $1,300^{\circ} \mathrm{Fahr}$, which he himself thoroughly believed in as marking a change in the carbon. By the verification of this recalescence, coupled with the results of the microscopical research, he had arrived at the conclusion that, when steel was heated, the whole of the carbon was dissolved in the iron in some form; but on cooling, the actual fact was that the steel became separated into the alternating plates of pure iron and carbide of iron. On annealing, the constituents of the plates became more segregated, and the steel was softer. The present research he therefore considered, in order to be of practical value, should certainly be correlated with microscopical research.

A feature in the present report, which he considered almost as important as Le Chatelier's pyrometer itself, was the autographic recorder; and its admirable adaptation by Professor Roberts-Austen to the pyrometer would render this instrument he believed a boon to metallurgists and engineers. On the whole he thought that this method of observation, devised by M. Osmond and Professor Roberts-Austen, must rank as one of the means by which all samples of steel used in researches must in future be examined.

In the further prosecution of this research, what he wished particularly to recommend was a careful system of extensive correlation. The examination of the steel should comprise its chemical composition, its mechanical properties under varying conditions, whether annealed or unannealed or hardened, its microscopical features, and its characteristics in respect of recalescence. If this was done-and as far as he knew there was no insuperable difficulty in the way of doing it-then scientific metallurgical research would become a practical reality to engineers; and would result in good sound work, such as better material for rails or for bridges or for shop tools. This was the direction in which he considered that all research into iron and steel should be pursued. 
Mr. Charles E. Stromeyer had recently compiled the accompanying table, which might be of interest in connection with this disenssion, for showing generally the influences of the various impurities in mild steel. These data he had oollected from papers

\section{Influence of Impurities}

on some of the Properties of Mild Steel.

\begin{tabular}{|c|c|c|c|c|c|c|c|c|c|c|c|}
\hline \multirow{2}{*}{\multicolumn{3}{|c|}{$\begin{array}{l}\text { EIeme'it } \\
\text { constitnting } \\
\text { Impurity. }\end{array}$}} & \multirow{2}{*}{ 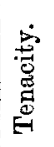 } & \multirow{2}{*}{ 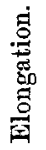 } & \multirow{2}{*}{ 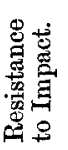 } & \multicolumn{3}{|c|}{ Pliability. } & \multirow{2}{*}{ 苞 } & \multirow{2}{*}{ 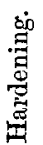 } & \multirow{2}{*}{ 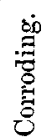 } \\
\hline & & & & & & Cold. & $\begin{array}{l}\text { Red } \\
\text { Hot. }\end{array}$ & $\begin{array}{l}\text { White } \\
\text { Hot. }\end{array}$ & & & \\
\hline Carbon & • & & + & - & - & $\rightarrow$ & & - & - & + & - \\
\hline Silicon & . & & + & - & - & & - & $-?$ & 0 & + & \\
\hline Arsenic . & - & 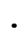 & + & - & - & - & & 0 & & - & \\
\hline Phosphorus & - & . & + & - & - & - & 0 & - & & & \\
\hline Sulphur . & . & & 0 & 0 & & 0 & - & 0 & - & & \\
\hline Copper . & - & & + & - & & & - & - & 0 ? & & \\
\hline Manganese & - & & + & + & + & & + & + & 0 & - & $?$ \\
\hline Nickel & - & • & - & + & + & + & & & & - & - \\
\hline Chromium & - & & + & 0 & + & + & & & & + & \\
\hline
\end{tabular}

+ denotes that the property is increased by the impurity.

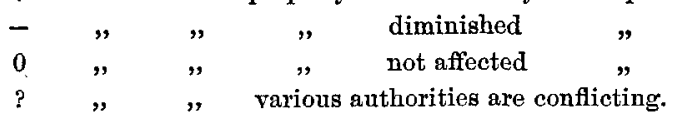

read before various societies; but with many of them he did not agree, particularly in those cases where the authorities were conflicting. In this compact form however he hoped the table might prove useful, and might be completed and corrected. Amongst the doubtful cases was silicon, of which it had not been definitely ascertained whether it diminished the pliability of mild steel at a white heat, or in other words whether it produced red shortness. Similarly the evidence was conflicting as to whether copper affected the welding qualities of steel; and also as to whether manganese affected its susceptibility to corrosion. The table might also with advantage be extended to include not only other elements but also 
other properties, such as melting point, viscosity, limit of elasticity, toughness, \&c. Moreover it appeared to him that no one impurity could be said to produce a certain effect when other impurities were present. It seemed as if some of the ingredients intensified, reduced, or entirely reversed the effects of others. Thus the tenacity and hardening qualities were increased, and the elongation and pliability reduced, by carbon; while a further admixture of manganese reduced or reversed all these effects except the increased tenacity. Tungsten and some other ingredients, not included in the table, appeared to agree with silicon and chromium in increasing the property of hardening which carbon gave to iron, and to reduce some of the othe $\mathbf{r}_{\mathbf{r}}$ properties.

The experiments which had been described in the report constituted in his opinion a new test, which he hoped would help to throw a great deal of light on the properties of steel; for there were various questions which could not be investigated by the tensile or bending tests or by any of the other tests hitherto employed. Thus steel plates often failed cold after flanging; yet when subsequently cut up and tried by tensile, bending, and other tests, the steel was invariably found to be of the best quality. In the bending test he had recently asked friends to try whether any further information could be gained by nicking specimens before bending them. Several results had been sent him, from which it appeared that thin plates of mild steel when nicked could be broken only after bending them through a large angle, if the samples had been properly annealed after being cut off the plates. But thick plates when nicked broke easily under the bending tests. Samples an inch thick could be bent perfectly double without breaking, if they had not been nicked; but if nicked a sixteenth of an inch deep, they broke off short. Pieces cut from plates only half an inch thick could be bent to a right angle after being nicked. In some of these bending experiments three qualities of steel had been tried, having tensile strengths of 24,28 , and 32 tons per square inch; and twelve samples were tested of each quality. It was found that the results agreed fairly well with one another in each of the three sets; but strangely enough the hardest material bent through a larger angle than the medium 
(Mr. Charles E. Stromejer.)

quality. This would show that the nicking of annealed samples before bending would disclose some property of the material not revealed by either the tensile or the temper bending test. It remained to be seen whether this test could be useful in any way for ascertaining the quality of steel; it appeared to him to be a sensitive test, but the data were not yet sufficient. Another test which might throw light upon the quality of the material was to measure its behaviour while being chipped or machined; for it was well known that mild steel was much tougher than iron, although of almost the same chemical composition; and mild steels of identical composition differed so materially in this respect, that with a little experience workmen could tell by chipping a plate in what district it had been manufactured. The difference in toughness might be due, amongst other causes, to the heat at which the steel had been worked; for it seemed a fact that the tenacity of the metal was greatly affected by this cause.

In regard to the experiments made with the miniature ingot shown in Fig. 8, Plate 116, and illustrated by the curves in Fig. 13, Plate 119, it seemed to him that the thermo-junction wires leading to the centre of the ingot would acquire the mean temperature of that distance, and impart it to the junction, so that the latter would not indicate the actual temperature at the very centre of the ingot, but a somewhat lower temperature. The outer hole was so shallow and so near the edge of the ingot that the temperature of the outside was probably shown correctly enough. In connection with the radiation of heat, he might mention some interesting experiments made by Mr. Thomas Andrews, of Wortley Iron Works, Sheffield,* as to the strength of axles at low temperatures. In one experiment a railway axle had been placed in a freezing mixture, of which the temperature was $-4^{\circ} \mathrm{Fahr}$., or $36^{\circ}$ below freezing point. In order that the cooling of the axle might take place slowly, it was surrounded by an air space of $\frac{3}{4}$ inch. The temperature in the axle was measured with thermometers dipped into mercury, which was deposited in holes drilled in the axle; and in Fig. 19, Plate 123, he

* Procecdings Institution of Civil Engineers, vol. xciv, 1888, pages 180 and 192 
had plotted a representation of the observations recorded. It took $9 \frac{1}{2}$ hours to reduce the temperature of the axle from $32^{\circ}$ Fahr. down to zero, the freezing mixture remaining $4^{\circ}$ lower. A peculiarity which would be noticed in the curve, Fig. 19, was that certain humps occurred in it as the temperature fell: thus at $24^{\circ}$ and at $17 \frac{1}{2}^{\circ}$ there was a distinct break in the continuity. It might be that these irregularities were accidental, inasmuch as the experiments were not made for the purpose of ascertaining those points, but simply to produce slow cooling of the axle. Another instance had been mentioned by Professor Wedding, at the German Iron and Steel Institute at Düsseldorf in 1888. While explaining that, if a piece of steel which had been polished ready for the microscope were heated to the temperature of molten lead, the structure was far more clearly developed than before, he had remarked as a curious phenomenon that the rate of increase in temperature of the steel received a decided check at this point: so that it appeared as if there was a break in the curve of heating at the temperature of molten lead. In several curves however of the cooling of steel, which he had examined, he had not fonnd any breaks indicating recalescence. The instrument described in the report was one by which he thought it might be possible to detect whether there really was recalescence at any of the above temperatures or not.

Mr. J. E. Stead, Middlesbrough, considered that a great deal of good would probably result from investigation of the kind described in the report. Dr. Anderson's remarks (page 573) had shown how this process of investigation might at once be utilised. With regard to the classification of carbon and other elements into the two classes given in page 544, he thought M. Osmond had in view only their effect in delaying the change of iron from the hard to the soft condition, and not any other effect. Mr. Hadfield's suggestion of re-classifying them, according to the other effects they produced upon steel, would be found most valuable. No doubt they would have to be arranged into a great number of classes. It would not be sufficient to study the effect of only onelor two elements; but after these had been studied most thoroughly, a third element must be introduced, and 
(Mr. J. E. Stead.)

then the study be begun entirely over again. The combinations in iron and steel were most extraordinary; and the investigation if properly carried out would be so elaborate that few of those present would be likely to see it finished. Mr. Hadfield's remarkable investigations had shown clearly that manganese produced certain effects in iron up to a certain percentage, but different effects with a larger quantity. Investigations with alloys of iron and other metals than manganese must be made in a similar way, right through the whole class, before it could really be understood what effect any particular element had upon iron. In his own experience in the manufacture of steel he had found most extraordinary differences in steel of identically the same chemical composition. Cases of this kind he considered should be carefully investigated; and he believed that the method of investigation described in the report, by means of the thermo-electric pyrometer now exhibited, might throw some light upon the real differences. At present it was very difficult indeed to find out invariably why one steel should be good and another bad.

Mr. J. Macfarlane Gray thought there was not more theory (page 572) in the report now read than in the paper discussed on the previous evening. The method of experiment described in the report was most interesting to himself, because it opened up a way to get at some definite knowledge regarding the constitution of matter and its molecular aggregations. A hypothesis, according to which every physical phenomenon was the result of enormous pressure in the universal ether, had been promulgated in his own paper on the ether-pressure theory of thermodynamics, in which he had shown that a change of molecular aggregation might be a change of effective volume in respect to the ether (Proceedings 1889, page 386). The steps in the cooling diagrams illustrating the present report denoted, in his view, that the total area of matter surface exposed to the ether permeating the molecular interstices was at the same time diminishing abruptly: a diminution of etherbounding area being necessarily accompanied by evolution of heat, and vice versâ. When the small amount of this implied diminution 
of effective volume was regarded, and was compared with the mechanical equivalent of the heat thereby evolved, the conclusion was forced upon his mind that the pressure of the ether must be of the order of billions of tons on the square inch. Staggering as this statement was, it was corroborated in every phenomenon of physical science. He believed it would be on the lines of thought set out in his paper on the ether-pressure theory that the features of the cooling diagrams now exhibited would ultimately be explained. In his further paper on the rationalization of Regnault's experiments on steam (Proceedings 1889, page 399) he had attempted, as a test of the ether-pressure theory, to construct a rational formula for the pressure of steam at all temperatures, without any empirical constants. Up to about 28 atmospheres, the highest pressuro reached in Regnault's experiments, there was perfect corroboration of the formula (page 445); but above that point the pressures calcnlated by his own formula were much in excess of those arrived at by the extension of Regnault's formula, and the amount of the disagreement was shown in page 447. In the Comptes Rendus of 25th May 1891 (page 1170) were published the experiments of MM. L. Cailletet and E. Colardeau, made at the Eiffel tower with the use of an open mercury column for pressures; and up to 200 atmospheres their observations of pressure were much more accurately represented by the formula given in his own paper of 1889 (page 440) than they were by the empirical formula constructed upon the experiments themselves and given in the Comptes Rendus of 24th August 1891 (page 328). This corroboration he hoped might tempt others to study that paper, so that it might be applied by some abler men than himself. In the pneumatic calking tool, which had been exhibited in the discussion yesterday evening upon boiler construction, he was glad to recognise a revival of the portable steam riveter exhibited by himself at the Dublin meeting of the Institution twenty-six years ago (Proceedings 1865, page 129); he had had it in use also as a pneumatic calker worked by compressed air. Now it came back from America much improved; and the improvements were appreciated by no one more highly than by himself as the originator. But if it should take another twenty-six years to bring 
(Mr. J. Macfarlane Gray.)

the ether-pressure theory similarly to the front again, he could not help wondering whether he should then have an opportunity of reminding the Members of his paper on the subject; he could only hope so.

Professor Robents-Austen, in reply, said that M. Osmond's classification of the elements alloyed with iron, which had been adopted in page 544 of the report, had been arranged only in accordance with observed facts in regard to the change of state in iron as indicated by the pyrometer. By careful chronographic record M. Osmond had found that the elements in column I did delay the change, and that those in column II did hasten it: those were observed facts. Copper, so far as physical experiments went, he himself quite, agreed was not a hardener (page 575); but then it came at the bottom of column $I$, its volume being $7 \cdot 1$, or so close to that of iron $7 \cdot 2$ that only a little more would have turned it over into the other class; its position therefore should be viewed with some leniency. While there was no evidence to justify the lowering of carbon from the position which it occupied as the steel-producing element (page 576), he considered that boron was entitled to a share in this property; though certainly carbon stood out with such prominence as to be almost unique.

With reference to the statement in page 544-that the elements in column II would act on iron as annealing did, rendering it soft and malleable, "did not their individual properties, or those of their compounds, mask this natural consequence of their presence" -this proviso he was aware qualified the classification adopted. But it must be remembered that nothing was known of the action of these elements in pure iron in such minute quantities as could be strictly compared with those of carbon. Steel almost ceased to be steel if the quantity of carbon exceeded 1.3 per cent. A very hard steel would be produced by no more than 0.8 per cent. of carbon. The effects of other pure elements in so small a quantity were not yet known: that was a subject for future investigation. Again, no one had yet succeeded in getting much chromium or much tungsten into iron, without the simultaneous 
presence of a great deal of carbon. It was_ indeed most desirable to investigate the properties of all the compounds of iron with other elements; but the immediate object with which the present report had been started was to study molecular action; and this was the main object of M. Osmond's classification, which had been reproduced as a quotation in the report, and for which the Research Committee were responsible only as a quotation.

Both Mr. Hadfield and Mr. Stromeyer seemed anxious that the action of elements on iron should be classified; and although he himself considered that the time had not yet come for making such a classification, he nevertheless offered tentatively as a basis for the purpose the following scheme, which appeared to himself and to M. Osmond to possess certain merits. It was still based on the atomic volume of the added impurity; and it showed that, as the atomic volume of the added element augmented, the influence gradually ceased to be beneficial, and ultimately became absolutely prejudicial to the mechanical proporties of steel. It should be remembered that the atomic volume of iron was $7 \cdot 2$, a little larger than that of copper.

Added Elcment, Influence of the added Element. and its Atomic Volume.
$\left\{\begin{array}{l}\text { Carbon } \\ \text { Boron }\end{array}\right.$
$\left\{\begin{array}{l}\text { Nickel } \\ \text { Manganese } \\ \text { Copper }\end{array}\right.$
$\left.\begin{array}{l}3 \cdot 6 \\ 4 \cdot 1\end{array}\right\}$
Necessary for effecting the change of iron into steel.
$6 \cdot 7)$
$\left.\begin{array}{l}6 \cdot 9 \\ 7 \cdot 1\end{array}\right\}$
Useful under certain conditions: Nickel in Schneider armour-plates; Manganese in Hadfield steels; and Copper in Schneider steels for special uses.
$\left\{\begin{array}{ll}\text { Chromium } & 7 \cdot 7 \\ \text { Tungsten } & 9 \cdot 6\end{array}\right\}$
Useful in certain conditions, but rather by exerting a reflex action on the carbon, than by direct action of their own.
$\left\{\begin{array}{ll}\text { Aluminium } & 10 \cdot 6 \\ \text { Silicon } & 11 \cdot 2\end{array}\right\}$
Useful as reducers, but without much direct action. $\left\{\begin{array}{ll}\text { Arsenic } & 13 \cdot 2 \\ \text { Phosphorus } & 13 \cdot 5 \\ \text { Sulphur } & 13 \cdot 7\end{array}\right\}$
Prejudicial in all cases.

It had been questioned by Mr. Arnold (page 583) whether the plan thus far pursued in this research did not entail a great waste 
(Professor Roberts-Austen.)

of precious labour; and he had deprecated drawing analogies between the action of impurities on gold and on iron. With reference to such a view of the subject, Professor Roberts-Austen observed that those whose position as teachers gave hope that experimental work in the field of metallurgy might in the future be expected from them were too few already; and he wished therefore to say nothing that would discourage anyone at the outset of his career; but he would point out that the tone of Mr. Arnold's remarks would doubtless have been different, had he better understood the nature and object of the Committee's research, which was, as stated at the outset of the report, "to investigate the effects of small admixtures of certain elements on the mechanical and physical properties of iron, copper, and lead." The desire of the Committee, as pointed out in the next sentence, was to extend an investigation previously made upon the application of the "periodic law" to the mechanical properties of metals.

It was widely recognized that phosphorus, sulphur, carbon, boron, silicon, and other elements might be obtained chemically pure, and yet under variations of thermal treatment could be made to pass from their normal state to an allotropie one, in which their properties were entirely altered. This had already been illustrated during the present discussion by the well-known example of sulphur in its elastic form like india-rubber, and in its crystalline yellow condition, the sulphur being equally pure in both states. It might fairly be concluded that physicists in this country and in France had demonstrated that iron could exist in at least two distinct states. Professor H. Le Chatelier, while not attaching so much importance as he himself did to the effect of $\beta$ or hard iron on the hardening of steel, nevertheless stated that in manganeseiron alloys the iron must be present in the $\beta$ or hard form. Such men as Pionchon, Ditte, and Le Chatelier were satisfied as to the existence of allotropic iron, which was the basis of much of Osmond's recent work. Now if any metal under investigation could exist in two states, each with widely different properties from the other, it was absolutely necessary at the outset of any research to ascertain which modification of the metal was the subject of examination. 
Such an enquiry was nevertheless dismissed by Mr. Arnold (page 583) as wasteful of precious labour, and as offering small prospect of any good result, at any rate in connection with iron and steel. It appeared to Professor Roberts-Austen however, and the Committee entirely shared his view, that it was his first duty to collect experimental evidence for or against the existence of iron, copper, and lead, in allotropic conditions.

In the experiments which were relied upon as indicating the passage of iron from the $\beta$ or hard to the $a$ or soft state, it was urged by Mr. Arnold (page 585) that the thermal evidence of change afforded by the slight halt in the fall of temperature at the point $d$ in Fig. 12, Plate 118, was too small to mark a gigantic internal convulsion. But, although arguments from analogy had been disparaged by him, it might interest him to learn that the profound molecular change which must occur during the passage of plastic sulphur to its crystalline state was attended by but little thermal disturbance. Time alone would show whether analogies were worth much or little in an investigation of this kind (page 583).

The autographic records of the cooling of pieces of steel, accompanying this report, represented precisely the same facts as the plotted chronograph diagrams illustrating Osmond's paper to the Iron and Steel Institute (Journal 1890, No. I, page 38); and all the data for obtaining curves similar to M. Osmond's were afforded in these autographic curves (page 584). In Fig. 12, Plate 118, the marked prominence at $650^{\circ} \mathrm{C}$. in the curve of moderately hard steel was due to the change in the relation of the carbon and the iron which took place as the mass cooled. The corresponding prominence at $f$ in the curve of very soft steel was less marked, because the latter contained so little carbon; but in some cases the heat evolved during the occurrence of the carbon change was sufficient to raise the temperature of the whole mass $100^{\circ} \mathrm{C}$. The amplitude of the smaller change at $d$, which occurred at the higher temperature of $843^{\circ} \mathrm{C}$., was doubtless greatly influenced by the simultaneous presence of impurity. This was a subject for future investigation; the point at present to be insisted upon was that this evolution of heat, which occurred when 
(Professor Roberts-Austen.)

the mass cooled down to about $850^{\circ} \mathrm{C}$., was seen in its most perfect development in iron in which chemists could barely detect the presence of carbon.

The facts mentioned by MIr. Arnold, in connection with the change in structure arising from alterations in the relation between the carbon and the iron, were well known, and had been generally accepted.

It had been pointed out by M. Osmond that, as the proportion of carbon increased in steel, two of the points of recalescence tended to become coincident; and steel containing 0.8 per cent. of carbon should have the maximum effect produced by the two changes when they coincided at about $750^{\circ}$ C. or $1,380^{\circ} \mathrm{Fahr}$. The carbon point of recalescence $f$, Fig. 12, Plate 118, denoting the change in the relation between the carbon and the iron, tended to shift upwards; while the higher point of recalescence $d$, which was believed to mark the change of what he thought was hard iron into soft iron, tended to shift downwards, approaching the carbon point $f$, until they united and augmented each other.

Only two or three pages of the present report had been devoted to the consideration of steel, in regard to which he had recorded the recent experiments he had himself made in the light of M. Osmond's previous investigations. But in a lecture which he had delivered before the British Association at Newcastle-on-Tyne in 1889, on the hardening and tempering of steel, he had exhibited a number of large coloured diagrams in illustration of Dr. Sorby's admirable microscopic investigations (page 586). These had not been referred to in the report, simply because they did not seem to him germane to the present stage of the investigation: in which he was not dealing with the effect of particular quantities of carbon on iron, such as formed steel, but with the effect of the molecular structure of iron itself; and even this only incidentally. It was partly that lecture however, he believed, which had led Dr. Anderson to recommend that the Alloys Research Committee should be appointed; and he would ask the members of the Institution to bear in mind that this was one of the first efforts ever made to. bring the study of molecular physics into contract with the great 
mechanical problems of the day. The Committee were investigating the molecular grouping of metals, which underlay their structure; and they therefore employed the pyrometer and not the microscope.

The remarks of Mr. Howe, to whom all English metallurgists who visited America were indebted for so many kindnesses, were enhanced in interest by the admirable volume on steel which he had given to the metallurgical world. There were indeed many anomalies yet to be explained. It was net known as yet what was the extent of the molecular transformations that phosphorus underwent in passing into solution, nor what was the effect of phosphide of iron. When all these questions were cleared up, the answers might be of service in explaining some of the existing anomalies. The investigations as to the existence of "osmotic pressure" in impure liquid metals were now being conducted by Messrs. Heycock and Neville and by himself. It could be shown that the atomic volume of the added impurity did affect the amount by which the freezing point of a metal was lowered (page 581).

As to the belief expressed by Mr. Macfarlane Gray (page 592), that the atomic volume of an element was altered when it was united by fusion with a mass of another metal, the modern investigation of "osmotic pressure," exerted by elements when dissolved in metals, seemed to show that the action of the added element was definite, and that the volume of the element in solution bore a simple relation to its initial volume.

The President said the report now read by Professor Roberts-Austen was only the commencement of this research, and no pretence was made of having reached finality on any point. But however unlikely it might be that either Mr. Macfarlane Gray (page 594) or himself would see the end of it, he certainly looked forwards to seeing at any rate some further instalments of it. Meanwhile he had great pleasure in asking the members to join him in giving their best thanks to Professor Roberts-Austen for this first instalment of his labours in the important research which had been started at the welcome suggestion of Dr. Anderson. 
Mr. WaLter BagshaW wrote to call attention to a phase in the behaviour of melted metal, which at present had been but little examined: namely the configuration on the surface of molten metal, particularly cast-iron, popularly known as "flowering," from the size and pattern of which some indication of the physical properties of the metal when cold might be gleaned. Some time ago he had endeavoured to photograph melted metal in his foundry; but, owing he believed to imperfect appliances, he had not succeeded in obtaining an outline visible to the naked eye. If a series of photographs of these casting flowers could be taken, and tabulated with the chemical analysis of the metal, the breaking weight and deflection of a test bar, and the photograph of its fracture, it seemed likely that useful information might be gained; for he was confident that there was more in the rough and ready inspection of the metal in the ladle than was admitted by those not practically engaged in the foundry.

Another point of interest, of which a satisfactory explanation would prove a boon to ironfounders, was the common practice in the foundry, when a casting free from blow-holes or other imperfections was required, to feed the mould with frequent supplies of fresh metal, which was pumped in by a rod worked up and down in the runner. During this operation the outside of the runner solidified and formed a tube, through which additional metal was forced into the casting; there was thus a liquid centre, surrounded by a solid exterior, with an intermediate pasty material, the three states blending in imperceptible gradations. The question arose whether a casting artificially fed in this manner was as free from internal strains as one left to undergo natural shrinkage. Practice would seem here to be opposed to theory.

Mr. Edwand B. Marten, Member of Council, wrote that it had occurred to him that sulphur-which in its crystalline or common condition and its elastic state had been referred to by Professor Roberts-Austen as illustrating allotropic forms of matter-was the agent which turned india-rubber from its elastic or common state into the exceedingly hard vulcanite now so much used in electric 
work. Was there any analogy between this effect and the effect of alloys on metals? and would microscopic investigation of these substances be likely to reveal any similarity of molecular structure to that of iron, or of iron with alloy of carbon in the form of steel? India-rubber being an organic compound might indeed be thereby excluded from comparison with metals; but even if the present investigation could not be at all assisted by the analogy of materials dealt with at such low temperatures, their analogy might at least help to make an abstruse subject somewhat clearer to the uninitiated, in the same forcible way in which, on a former occasion (Proceedings 1883, page 79), Professor Hughes had made clear his ideas of the effect and condition of molecules of iron and steel under electric influence, by study of iron filings loose and fixed with wax.

Mr. George Addy wrote that attention had been drawn by Professor Roberts-Austen in page 564 of his report to the interesting information afforded by the pyrometer in connection with the measurement of internal stresses in iron and steel ; and it was added that the occurrence of the molecular changes in steel must be of vital importance when the metal was subjected at high temperatures to mechanical operations such as rolling or forging. This was a subject on which reliable information would be highly acceptable; and the experiments which had been made with the miniature ingot of mild steel, four inches diameter and eight inches long, were certainly a step in the right direction. It appeared to him desirable however to point out that, although the upper curve in Fig. 13, Plate 119, was said to record the cooling of the centre of the ingot, what it actually did record was simply the cooling of the bottom of an open hole drilled down in the centre of the ingot. This hardly represented the centre of an ingot in the usual acceptation of the expression ; and the cooling thus recorded must in his opinion be altogether different from the actual cooling of the centre of an ingot, either in a state of quiescence or during the process of rolling or forging. Although between the points $A$ and $B$ in Fig. 13 the portions of the two curves that had been obtained from the two holes drilled in the miniature ingot as shown in Fig. 8, Plate 116, might afford some general idea of the great 
(Mr. George Addy.)

internal strain which must be set up during the cooling of a piece of steel of the size experimented upon, such an indication he considered must not be taken as applying to a real ingot just turned out of the mould. If it were possible to record, simultaneously with the heat of the exterior, the heat also in the interior of an ingot during cooling - not of a hole drilled in the centre of an ingot-a different condition he believed would be revealed from that represented by the portion of the curves between A and B in Fig. 13.

When making a series of experiments about two years ago with armour-piercing projectiles, for which a pyrometer that could be relied on for high temperatures would have been most useful, he had found as the result of enquiry that no trustworthy pyrometer could be obtained except for comparatively low temperatures. It had consequently been necessary to make other arrangements, which, although satisfactory in the long run, had entailed considerable trouble and anxiety at the time. He was glad therefore to hear of the accuracy of the Le Chatelier pyrometer now described, when used for high temperatures.

This report opened a wide field for investigation; and he trusted that Professor Roberts-Austen and other members of the Research Committee would shortly communicate further information on steel, as this appeared to be the material which most closely interested mechanical engineers.

Professor Alexander B. W. Kennedy, Vice-President, wrote that of the many points of interest opened up by the work done by Professor Roberts-Austen for the Alloys Research Committee he should like to emphasize one only. The investigation really seemed to him to bring engineers somewhat nearer to the causes of one of their great troubles, namely the existence of latent stresses in materials supposed to be unstrained. If Dr. Anderson's suggestion (page 573) conld be carried out, it might be possible to find ont, by the behaviour of turnings or other small portions of a material, whether its physical nature had been altered: whether for instance, if a bar of iron were bent cold, any change took place at the bend to cause it to differ from the unbent part of the bar. Or, perhaps even in cast-iron, 
whether the different rates of cooling in different portions of a casting left such traces in the constitution of the metal as could afterwards be detected by the extraordinarily delicate apparatus now exhibited. He did not understand Professor Roberts-Austen to say that he could already go so far as this; but he hoped that further work in this direction might enable some results of the kind to be obtained. Would turnings from the fractured surface of a test bar, for instance, which was always somewhat strongly magnetic, give results with the thermal method different from those given by turnings from other portions, strained or unstrained, of the same bar? Though be had not himself used the thermo-electric pyrometer, he hoped to do so: among other purposes, for measuring the temperature of flue gases.

From the promising start already made, the work of the Alloys Research Committee he thought would prove at least as important as that of any of the other Research Committees of the Institution; and he looked forwards with much interest to further communications from Professor Roberts-Austen.

Professor Roberts-Austen wrote that the interesting remarks of Mr. Marten (page 600) seemed to be much to the point, for it was more than probable that the effect of sulphur on india-rubber presented analogies to the influence of carbon on iron; but the problem was one of such terrible complexity as to deter workers from attacking it at present. Moreover it must be remembered that the percentage of sulphur in india-rubber was large. As an organic compound, india-rubber was by no means excluded from comparison with compounds of carbon and iron, which were almost organic in their nature; and the general tendency of modern research was to break down the distinction which had hitherto existed between alloys and organic compounds.

In regard to Mr. Addy's recognition (page 601), which was much appreciated by himself, of the value of the experiment represented in Fig. 13, Plate 119, it was of course true that the upper curve represented the cooling at the bottom of a hole drilled down in the centre of the ingot, and that this hole was not absolutely closed. It could not be said however to be an "open" hole, for it was filled as 
(Professor Roberts-Austen.)

nearly as might be by the pyrometer wires and their insulating tubes; and it was for the sake of clearness that the size of the orifice was exaggerated in the drawing. Filling such a hole with a fusible metal, as was usual in conducting physical experiments at comparatively low temperatures, so as to ensure complete thermal con'act, would not have met the case. 


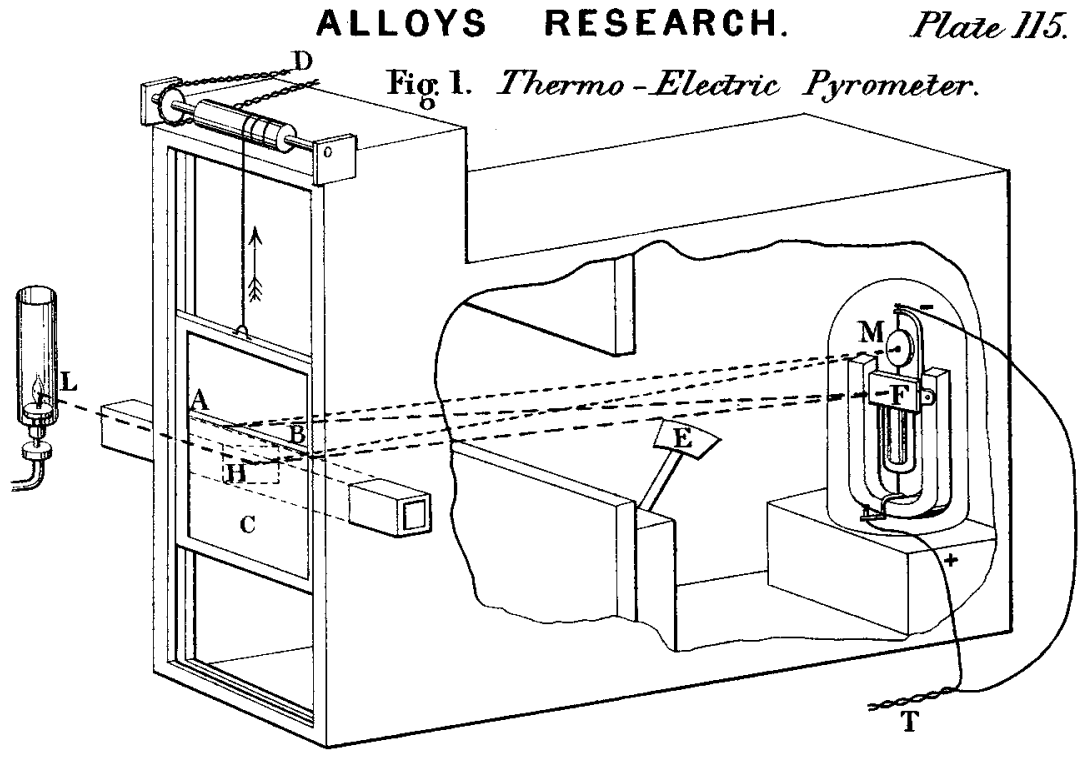

Fig. 2. Calibration of Pyrometer.

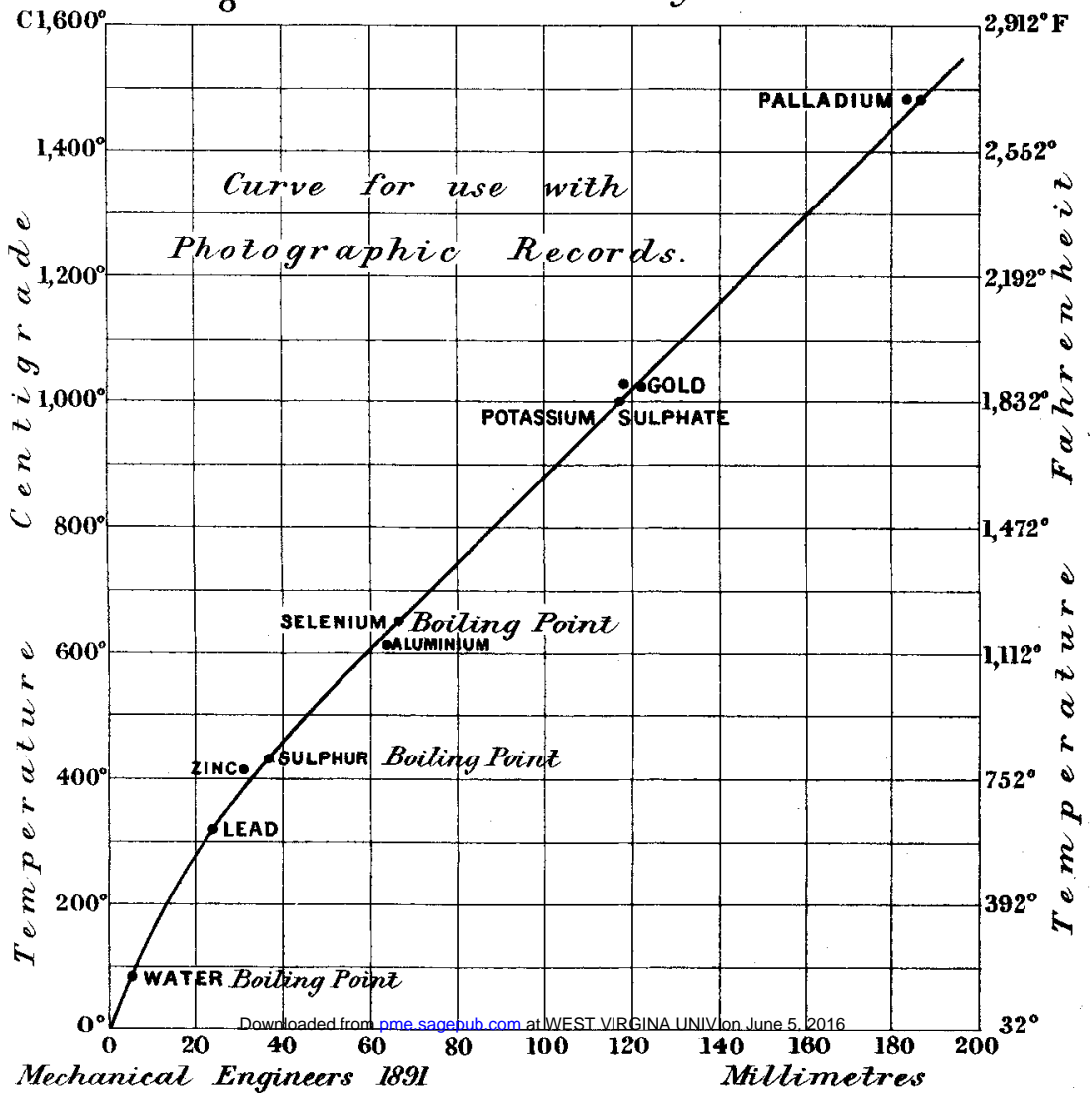


Thermo-couple.

Fig. 3.

Fig: 6.

Crucible.

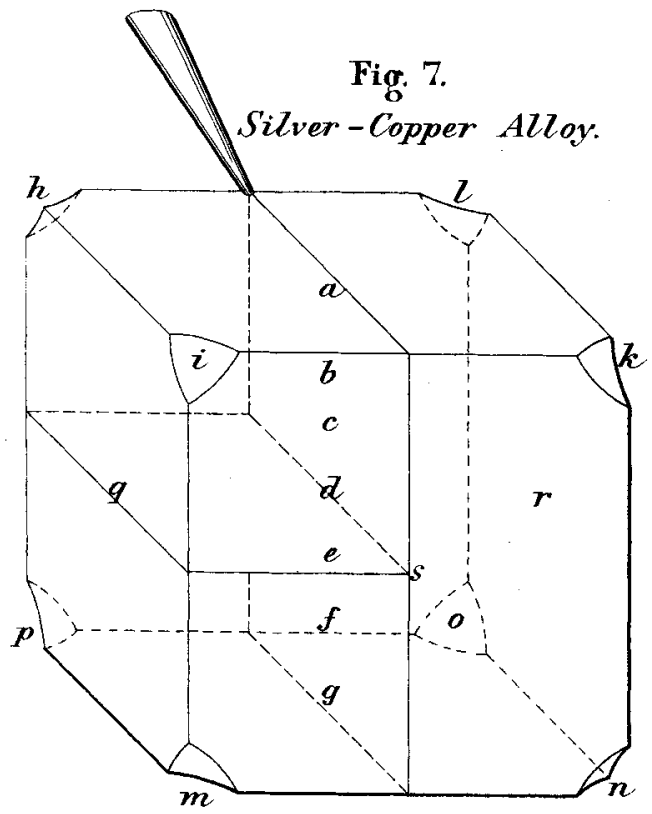

Fig.
8
8
8
7

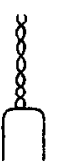

Fig. 5.

Gatvanometer.

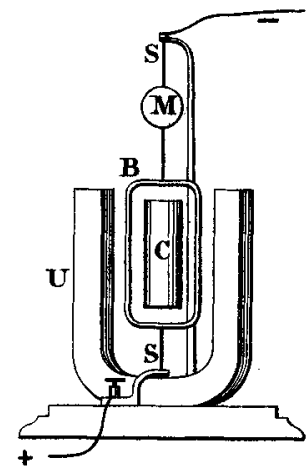

Fig. 8.

Section of Ingoz.

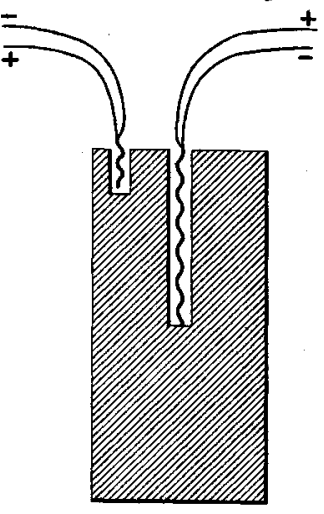

Fig. 9.

Fusion and

Solidification

of Aluminium.

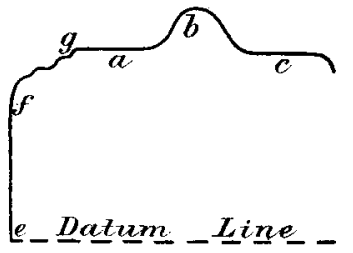


ALLOYS RESEARCH.

Plate IIT.

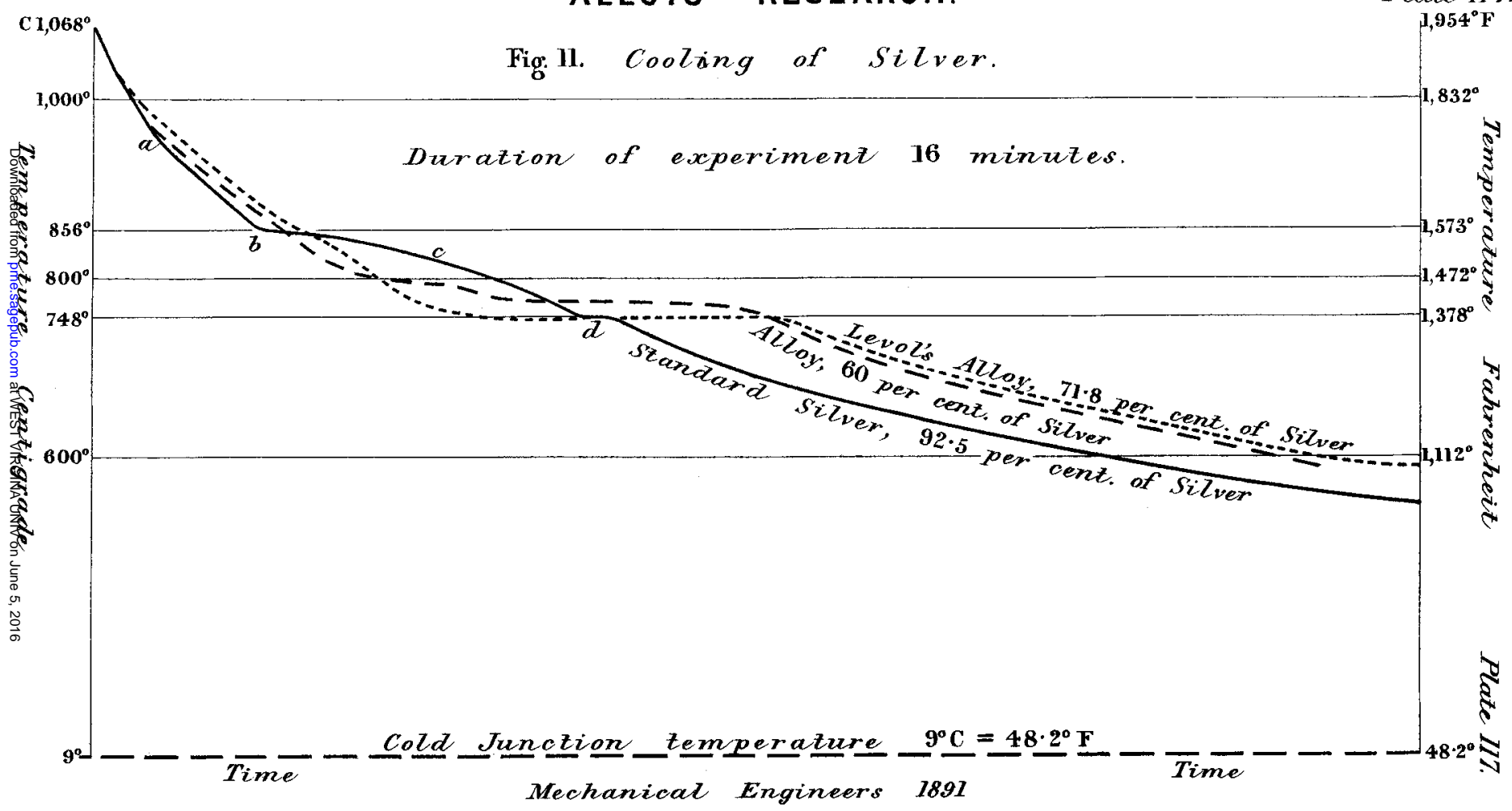


ALLOYS RESEARCH.

Plate 118.

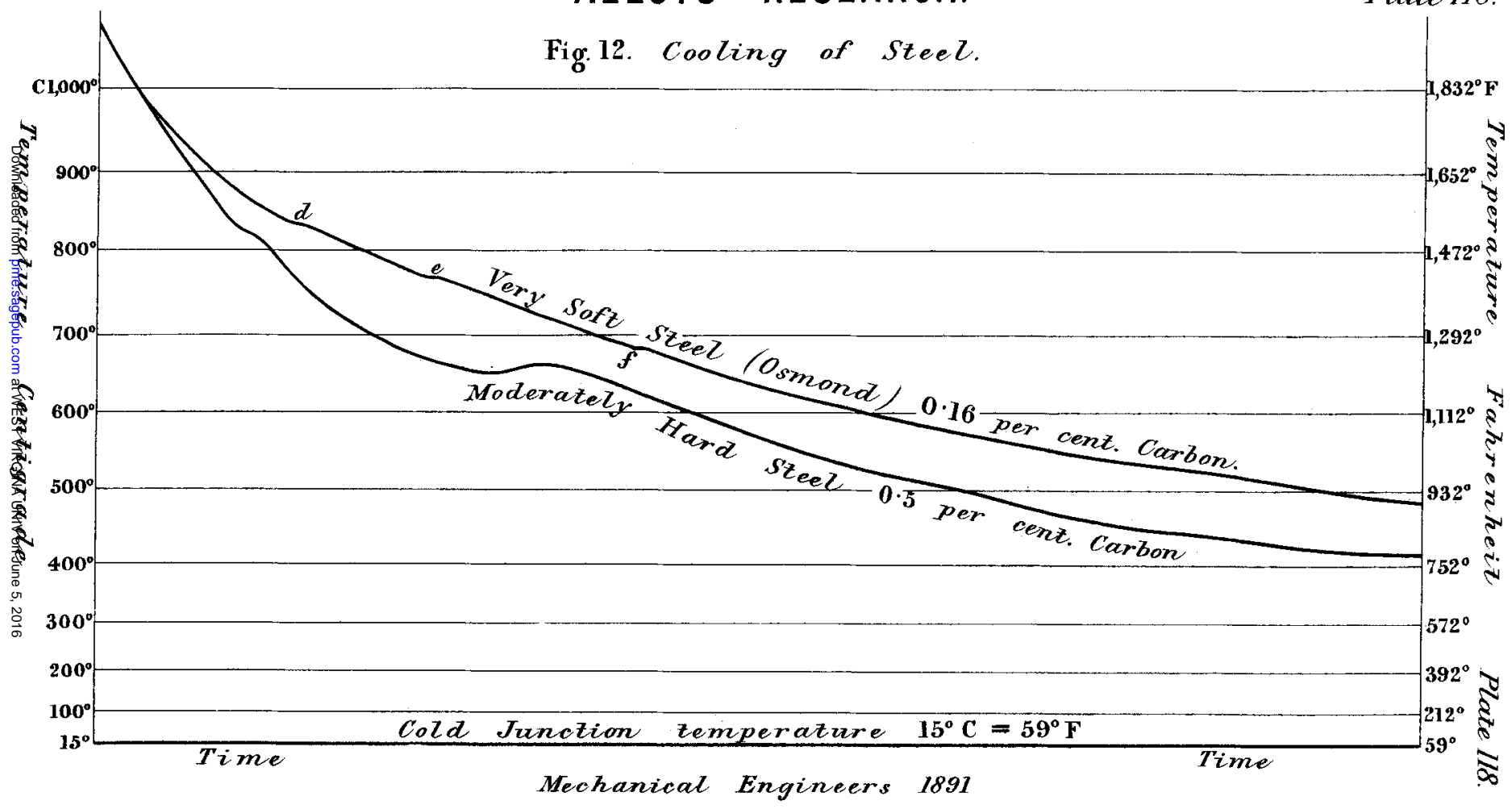




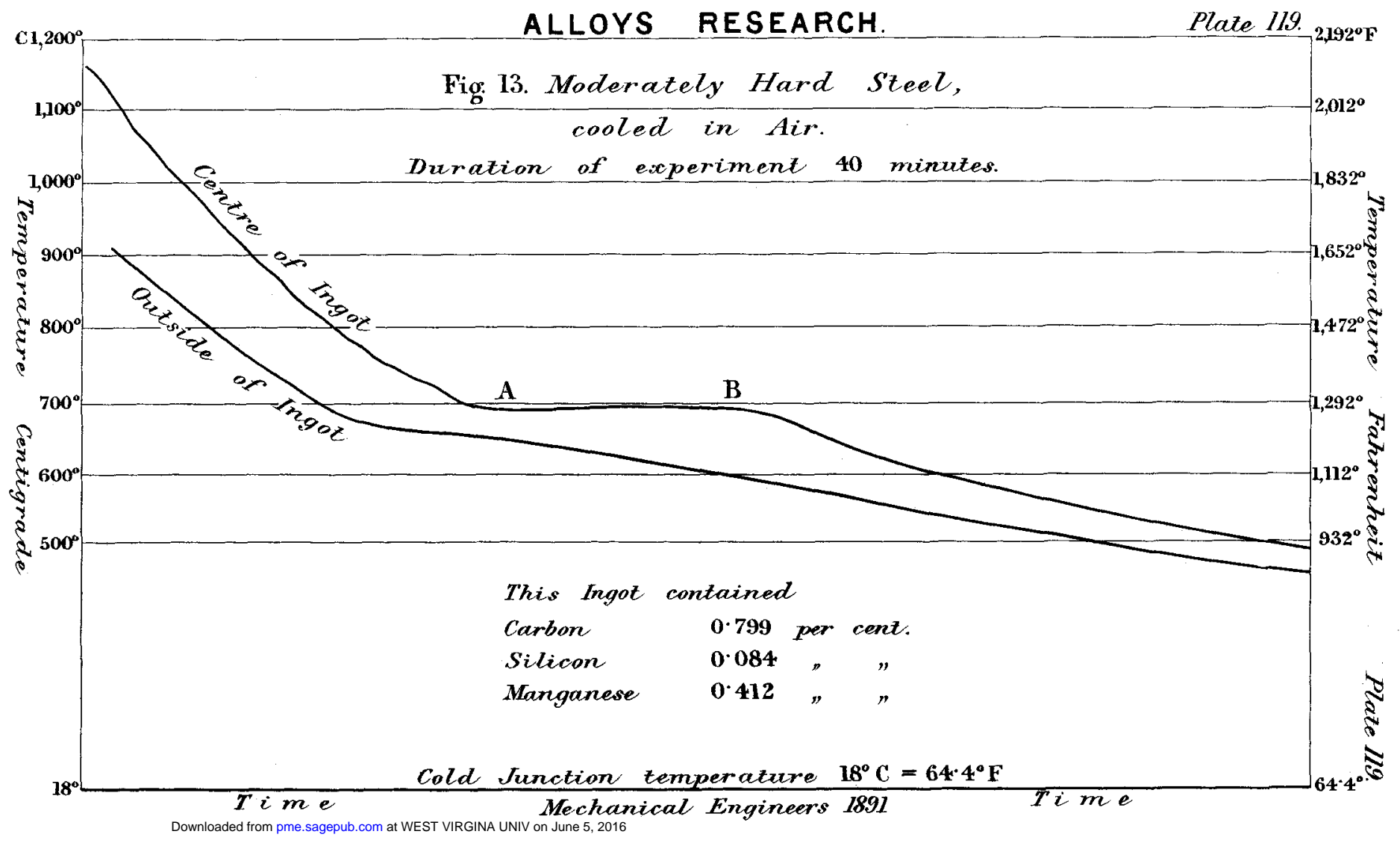


ALLOYS RESEARCH.

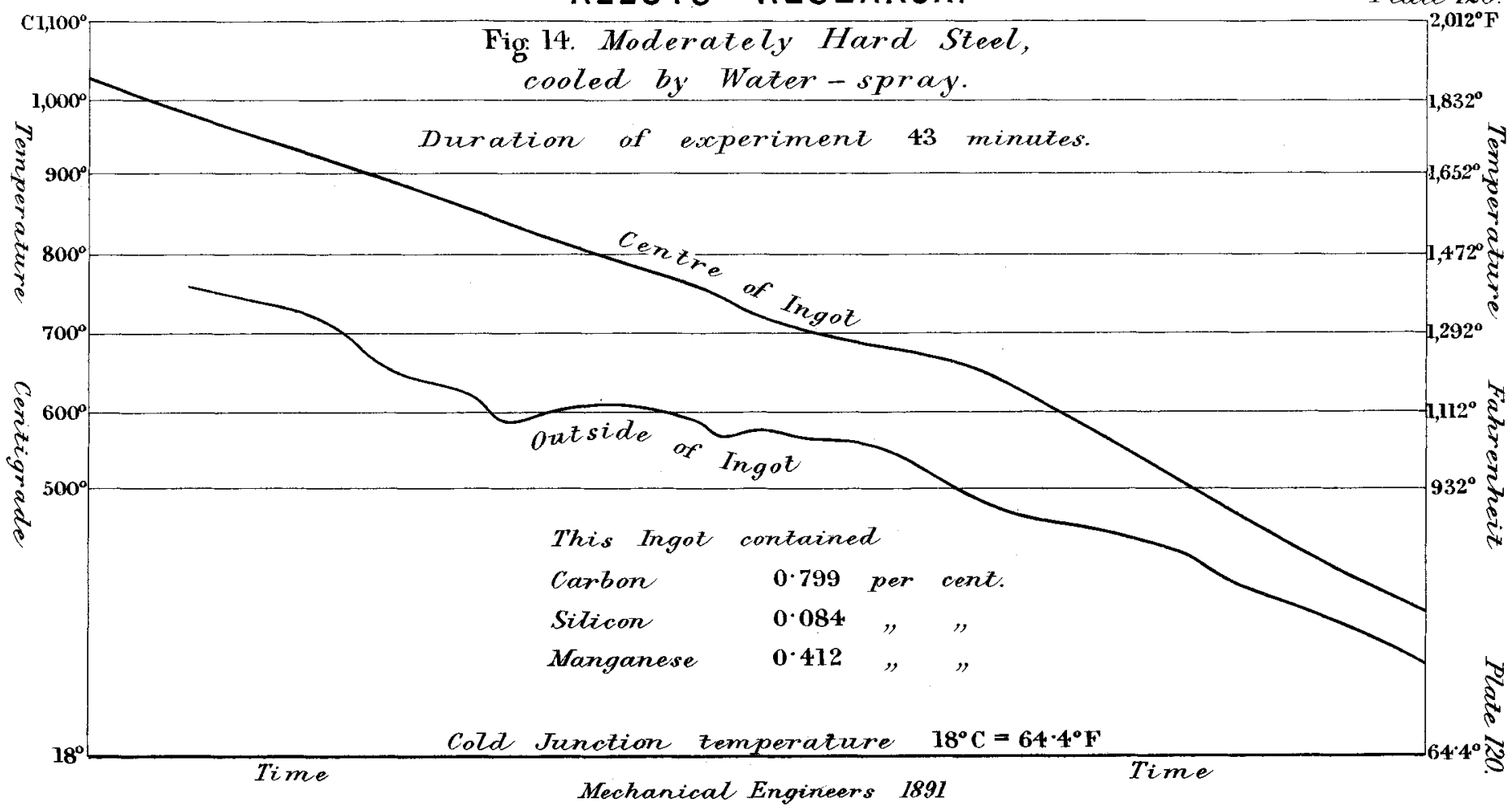

Downloaded from pme.sagepub.com at WEST VIRGINA UNIV on June 5, 2016 


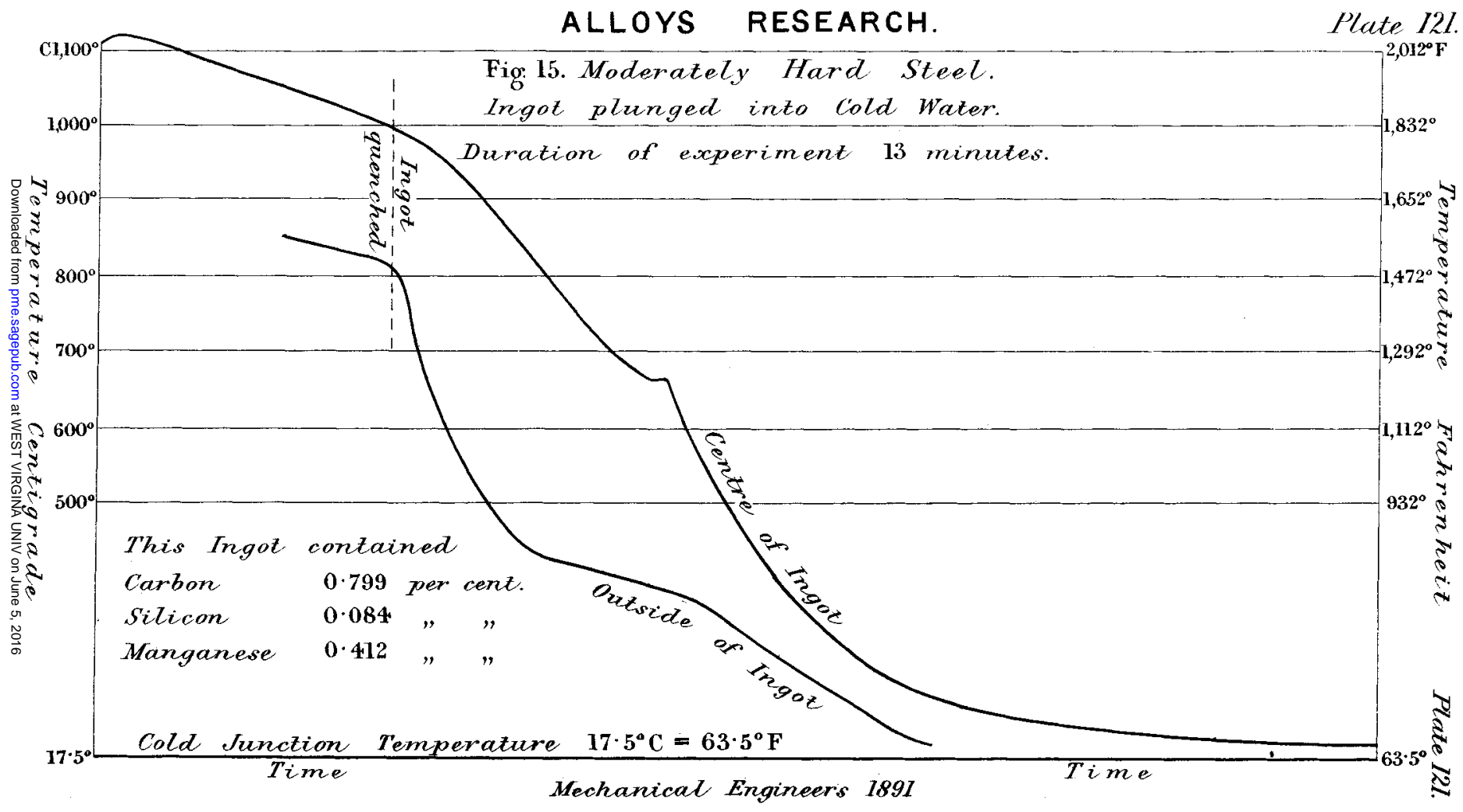


ALLOYS RESEARCH.

Plate 122.

Fig: 16. Atomic Volume of Elements

and Tensile Strength of Gold alloyed with 0.2 per cent of each.

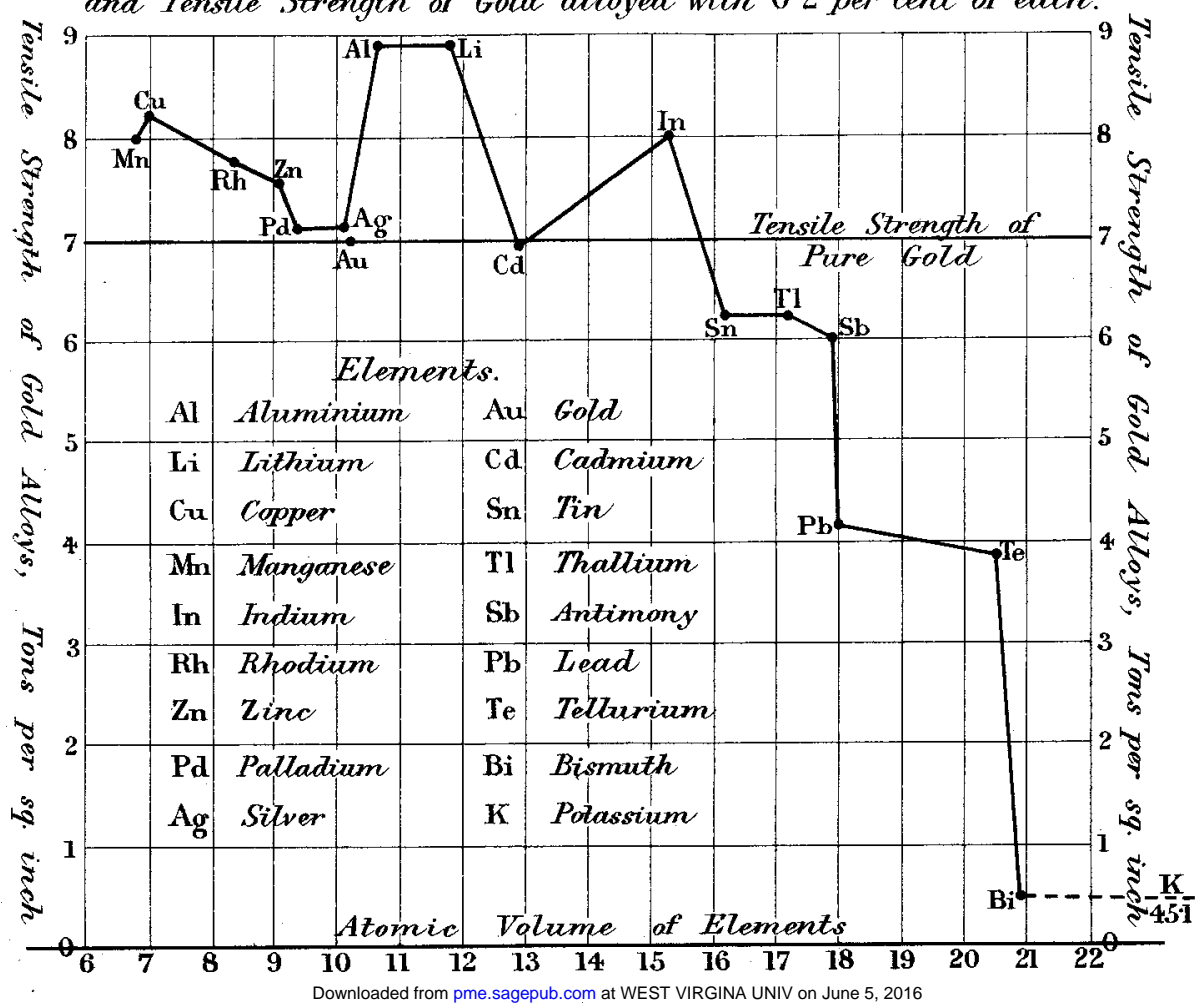

Fig: 17. Electro-deposited Iron

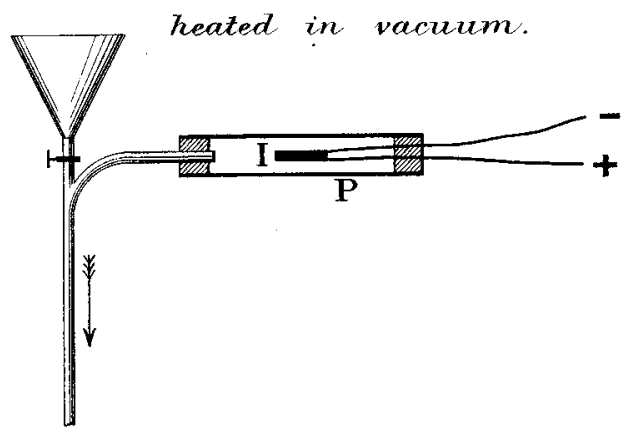

Fig. 18. Heating and Cooling of Electro-deposited Iron.

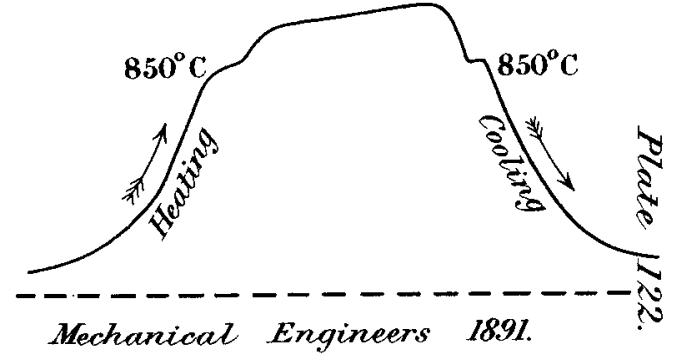


ALLOYS RESEARCH.

Fig: 19. Cooling of Railway Axle.

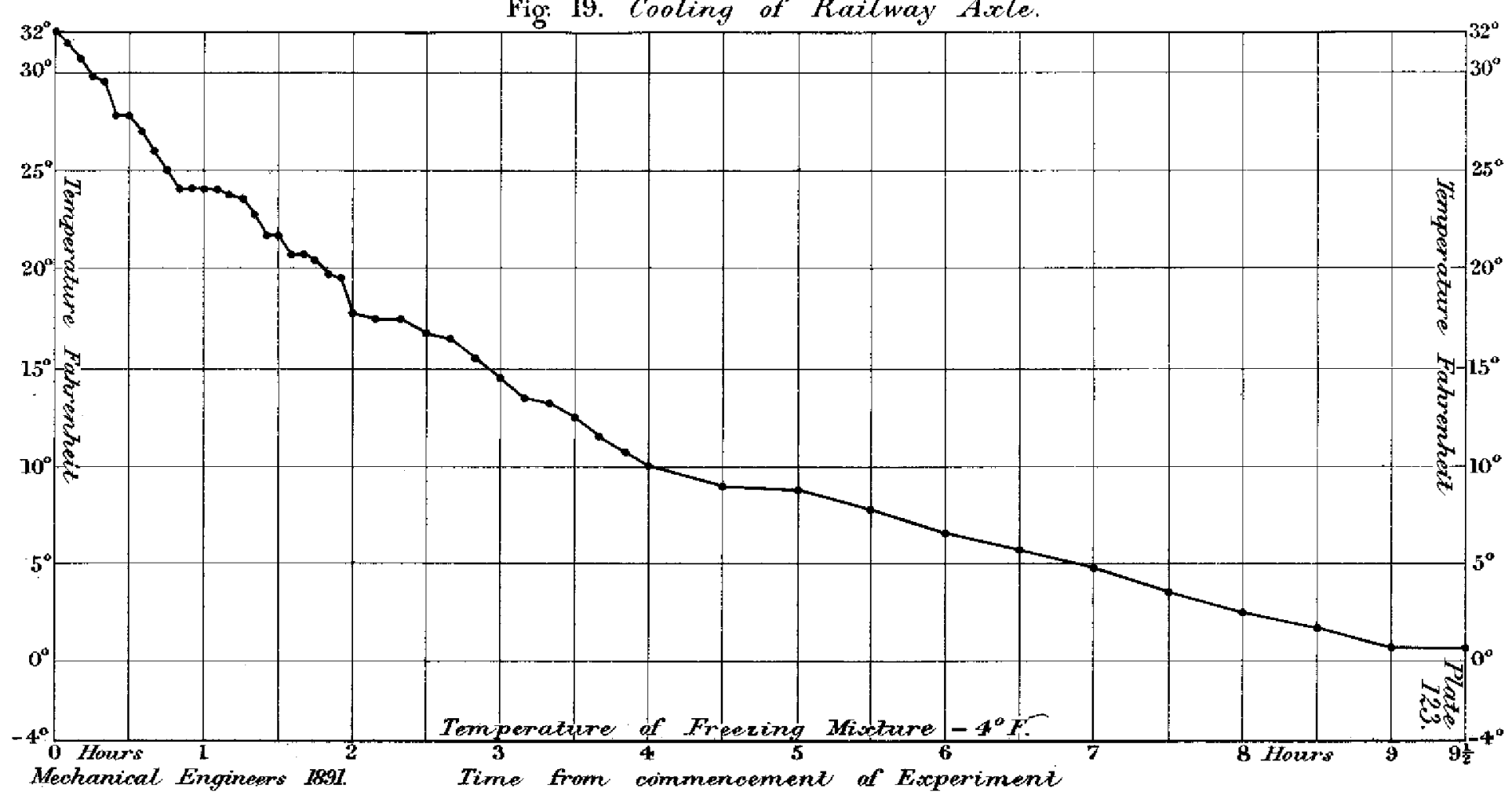

Downloaded from pme.sagepub.com at WEST VIRGINA UNIV on June 5, 2016 